\title{
Insects - a mistake in God's creation? Tharu farmers' perception and knowledge of insects: A case study of Gobardiha Village Development Committee, Dang-Deukhuri, Nepal
}

\author{
Astrid Björnsen Gurung \\ Mountain Research Initiative (MRI), Berne, Switzerland
}

Accepted in revised form October 25, 2002

\begin{abstract}
Recent trends in agricultural research and development emphasize the need for farmer participation. Participation not only means farmers' physical presence but also the use of their knowledge and expertise. Understanding potentials and drawbacks of their local knowledge system is a prerequisite for constructive collaboration between farmers, scientists, and extension services. An ethnoentomological study, conducted in a Tharu village in Nepal, documents farmers' qualitative and quantitative knowledge as well as perceptions of insects and pest management, insect nomenclature and classification, and issues related to insect recognition and local beliefs. The study offers a basis to improve pest management programs in terms of efficacy and acceptance. It demonstrates, for instance, that a concept of pests and beneficials is virtually missing in traditional farming communities and that the Tharu folk classification profoundly differs from the scientific classification, but is not radically different from other folk entomological systems. Insects belong to the taxa called kiraa consisting of arthropods and nonarthropods that interact with humans. They are classified in several overlapping hierarchies where locomotion and human impact play major roles while morphological criteria are almost irrelevant. Recognition of kiraa, however, is dominated by agricultural aspects followed by physiological-behavioral, ecological, and humandirected features. Morphological criteria play a minor role. In nomenclature, however, the insects' physical appearance is more important than other features. The study further shows that male and female farmers have different perceptions of kiraa. The insect-related knowledge system of the Tharu has prevented farmers from using modern pesticides in the past. In the course of modernization, however, some aspects of their knowledge system could become obsolete and prove disadvantageous to their livelihood and agro-ecosystems.
\end{abstract}

Key words: Cognitive anthropology, Ethnoecology, Ethnoentomology, Folk taxonomy, Gender, Indigenous knowledge, Insect pest management, Nepal

Astrid Björnsen Gurung, formerly affiliated to the International Centre of Integrated Mountain Development (ICIMOD) in Nepal, is an Environmental Scientist and Development Specialist working for the Mountain Research Initative, Switzerland.

\section{Introduction}

People's knowledge of insects varies in quality and quantity depending on their interest in the subject, their environment, and the relevance of insects to their lives. Many people separated from the natural world conceive insects as insignificant creatures that go unnoticed unless they cause problems such as a sting, a bite, or annoyance. Other people, mostly from the urban West, take insects to be an immediate danger to their hygienic living space and some even develop an unreasonable fear of insects, referred to as entomophobia (Day et al., 2000). Pesticide dealers tend to perceive insects as a threat to food security and humankind. Entomologists, devoting their professional life to the study of bugs alone, are commonly viewed as strange fellows. It is clear that varying interest, motivation, ability, opportunity and prior knowledge, and experience have a tremendous impact on a person's knowledge acquisition and perception (Boster and Johnson, 1989; Garro, 2000).

Knowledge and perception of insects is an important issue for agricultural extension programs. Ample experience has shown that farmers' knowledge can differ profoundly from scientific knowledge (Chambers, 1997; Horton and Ewell, 1991; NazareaSandoval and Rhoades, 1994; Steiner and Scheidegger, 1994; Warren and MacKiernan, 1995), having significant implications for development. Both farmers' and scientific knowledge have strengths and weaknesses. This is the case, for instance, if farmers' knowledge that was valid in the past fails to adapt to the rap- 
idly changing environment. In Nepal, the introduction of improved varieties expressing a higher susceptibility to insect pests rendered much of rural farmers' knowledge and experience in the field of storage management obsolete. Reliance on scientific knowledge, however, can lead to wrong decisions too. In 1996, for instance, an alleged Brown Plant Hopper outbreak reported from the lowlands of Nepal caused a lot of anxiety in the Plant Protection Division of the Department of Agriculture. From the literature, the Brown Plant Hopper is known as a serious pest requiring a quick solution. After some field experimentation, however, the extensionists learned that this insect did not create a problem (Ooi, 2001), an insight local farmers had acquired long ago. These examples show that neither scientific nor farmers' knowledge is absolutely right.

More than Western scientists, rural farmers are aware of the weaknesses that may exist in their knowledge base (Warren, 1991). Eliciting these drawbacks can be imperative for the proper identification and definition of problems and for effective research and extension. Further, inputs targeting specific knowledge gaps can render information transfer more efficient, acceptable, and practicable for farmers (Bentley 1992; Sherwood, 1997). However, information transfer should occur in both directions. For most natural phenomena, farmers have their own frameworks within which they interpret and explain observations and facts. Former extension approaches (Transfer of Technology, Training and Visit System), building on one-sided information transfer from the extension agent to the farmer, failed to recognize, acknowledge, and incorporate farmers' concepts. This often resulted in negative self-esteem patterns for the farmers, though their knowledge and role as research partners are increasingly gaining recognition (Haverkort and Hiemstra, 1999). The majority of the farmers still perceive their knowledge and practices as inferior to externally promoted technologies. Acknowledging farmers' experience and wisdom as valid in their specific context and using their inputs, approaches, and ideas not only strengthens their self-esteem, but also contributes to a balanced research partnership between farmers and scientists.

A thin line separates farmers' knowledge from their beliefs. Much of farmers' knowledge may appear to us as a belief or as a simple superstition. However, as noted by Werner and Fenton (1970), a belief embedded in the local belief system is even more than knowledge due to the given supernatural sanction. What appears to be a silly story to the outsider is a reality to farmers - with a significant impact on their perception, decision-making, and action. Apart from local beliefs, socio-economic conditions, cultural values, and atti- tudes can be determinants in the adoption or rejection of new technologies or practices (Beets, 1990; Morales and Perfecto, 2000; Reichelderfer and Bottreill, 1985; Schoubroeck, 1999; Soedjatmoko, 1971; Thurston, 1992; van Huis, 1991: 96).

A precondition for research partnership between farmers and external actors is effective communication. Communication is partly based on using a common language. It is obvious, however, that different actors such as entomologists, agricultural extensionists, development experts, and farmers, speak their own specific languages. These languages can have a tremendous impact on how the world is perceived. Insect names, for instance, are carriers of classification principles and as such, reveal a lot about how people conceptualize living things in their environment. Language, however, does not only consist of names and words, but also of concepts and frameworks. As shown for Nicaragua, one pest can have a number of local names in a single region and different pests may be called the same in different regions (van Huis et al., 1982). In Guatemala, Morales and Perfecto (2000) found the communication between researchers and farmers hampered as the term "pest" was defined differently by the members of these two groups. Often, the farmer is expected to operate in our world, i.e., to overcome the problems of cross-cultural understanding (Rusten and Gold, 1995). However, there is a strong need that we adopt and speak their language. Exploring farmers' perception and knowledge allows us to clarify definitions, to use the proper language and the farmers' logical framework. All these elements facilitate communication and, thus, are very important for pest management programs.

To speak the language precisely, one needs to include people's perception. Perception is influenced by the individual's background, the cultural context, and social rules. Consequently, farmers' perception differs from the views and considerations of researchers and extensionists. Thus, statements such as "farmers are unconscious of losses caused by pest" (Chitrakar, 1990), "they tolerate high pest losses" (Ajibola Taylor, 1974; Brown and Marten, 1986), and "they consider the post-harvest problem to be of least importance" (APROSC, 1986) are assumptions based on the outsiders' perspective but hardly studied in depth. If farmers have these perceptions, they are crucial for priority-setting for both farmers and extensionists. If no attention is paid to pest control on the part of the farmer, as losses are perceived as irrelevant, there will be little point in launching pest control programs although pest damage might justify some action.

In sharp contrast to the vast amount of literature available on insect perception and response to out- 
side stimuli, farmers' knowledge, perception, and attitudes in the field of insect pest management have been scantily covered. The knowledge and skills of small farmers in developing countries were largely ignored in the early development era, although more attention has been paid to this in recent years. Systematic approaches in applied ethnoentomology are scarce and remain primarily the work of anthropologists. One early work on ethnoentomology was done by Wyman and Bailey (1964) studying folk classification of Navaho Indians, and Posey (1981) documenting the folk taxonomy of the Kayapó Indians of Central Brazil. Berlin did extensive ethnobotanical and ethnozoological field work among the Jívaro of Amazonas, Peru. Ethnoentomological work has been done on the Maya of the X-Hazil Sur y Anexos, Mexico (A. Ruiz and C. Ramírez, personal communication). More extensive work was done on edible insects (e.g., Ramos-Elorduy, 1984: 87, 97) and their medicinal value (e.g., Ramos-Elorduy et al., 2000; Motte-Florac and Ramos-Elorduy, 2002). Altieri (1990) set farmers' folk-entomological knowledge in a wider context by analyzing the agro-ecosystem in which the knowledge is embedded. Applied entomological research, that means research aiming to improve on-farm experiments by using folk taxonomy and farmers' concepts, was done with Honduran farmers (Bentley, 1993; Bentley et al., 1994; Bentley and Rodríguez, 2001). In the same vein, Nazarea-Sandoval (1995a) studied farmers' perceptions of insects as a part of her research on local knowledge and agricultural decision making in the Philippines. Price (2001) developed a conceptual and analytical framework for documenting and measuring knowledge shifts among Filipino rice farmers.

Within Asia, Nepal is one of the countries least affected by modernization. Located in the Himalayas, Nepal is characterized by a high degree of inaccessibility, marginality, and a rich cultural and biological diversity (Jodha, 1998). The inaccessibility imposes a certain degree of isolation and the necessity for selfsufficiency. Farmers' sustenance and welfare, therefore, crucially depend on local resources and knowledge that have remained widely untouched by the transitions that have taken place in the outer world. Farmers' knowledge of insects has not been studied so far, although subsistence farming and grain storage are the cornerstone of the livelihood of the majority of Nepalese people. Yield and stored products are severely threatened by insect pest attack as the subtropical climate of the lowlands and hills of Nepal favors pest population growth. Nonetheless, farmers remain relatively passive and interventions regarding pest control are rare for unknown reasons. It is not clear if farmers are unwilling to consider or simply not capable of taking control measures. Similarly, farmers' perception of pests and actual losses are unknown. Basic work, such as insect folk taxonomy, is missing and it is unclear whether farmers perceive pest insects as a threat to yield and stored products, or as fellow creatures with a legitimate claim for their fair share.

The present case study will contribute to an understanding of Tharu folk taxonomy and farmers' knowledge of insect behavior, dynamics, and relationships. The research focused mainly on farmers' views and concepts based on their experience taking into account the variability of gender, age, and education in quantitative knowledge. Qualitative knowledge, however, is described as a composite picture, that means, as the amalgamation of individual competencies. Consequently, farmers' knowledge documented here exceeds the individual farmer's knowledge by far.

In this paper, terms such as "indigenous," "local," or "traditional knowledge" are substituted by "farmers" knowledge." Although there are numerous indigenous groups with distinct cultures and identities, the geographical patchwork of castes and ethnic groups makes it difficult to make a clear distinction between them, let alone to attribute their knowledge as "local." Similar problems are raised by the attribute "traditional" as it implies antiquity, i.e., an undisturbed continuum of the system over a long period (Balée, 2000; Gill, 1993; Johnson, 1992; Tamang, 1993; Warren, 1989). Nepalese farmers' knowledge, however, is influenced by knowledge outside the area, constantly evolving and by no means static or exclusively local.

\section{Methodology}

\section{Study site}

The research took place in Gobardiha Village $\left(82^{\circ} 37^{\prime} 43^{\prime \prime}\right.$ E, $\left.27^{\circ} 48^{\prime} 37^{\prime \prime} \mathrm{N}\right)$, Dang-Deukhuri District. The village, a dense cluster of 150 households south of the Rapti River, is situated at $270 \mathrm{~m}$ altitude at the foot of the hill ranges in Nepal, two hours' walk away from the main road. It is inhabited by the Tharu, one of the largest ethnic groups in Nepal. The Tharu speak their own language and have developed a unique culture characterized by a close relationship with nature. Because of the relative isolation of this subtropical low-land belt (Terai), a previously malaria-infested jungle avoided by other people, the Tharu remained the least known group in Nepal until recent times (Gurung, 1994; Krauskopff, 1999; Srivastava, 1999). Their present lifestyle bears witness to the past, when shifting cultivation was their main land-use strategy. The houses still have a temporary character and people 
shift with limited effort. In the area around Gobardiha, shifting cultivation was abandoned a few generations ago.

The importance of forests, mostly Sal (Shorea robusta) forests (lower tropical level) and Siwalik tropical deciduous forests (upper tropical level) (Dobremez et al., 1985), is limited to firewood and edible plants. Hunting is irrelevant as they rear livestock at their homesteads. Since the land reforms of the $1960 \mathrm{~s}$, it is prohibited to turn virgin forests into agricultural land.

Unlike other farming systems in Nepal, Tharu agriculture is less dependent on monsoon rains, as the villages are situated close to major rivers facilitating irrigation. Moreover, rivers are important for fishing, a core element in the Tharu way of life.

In the past, rice was the main staple crop and there is historical evidence that the alluvial soil of the lowlands brought forth sufficient yield, placing the Tharu in a good economic position (Krauskopff, 2000; Panjiar, 2000). Until a few decades ago, granaries were filled with one rice harvest per year, leaving the fields fallow during winter. Broadcasting of seed was practiced instead of transplanting seedlings (Krauskopff, 2000; McDonaugh, 1999) giving further evidence of relative food security in the past. The situation changed tremendously after the land reforms. Today, the Tharu are tied to their limited land and the landlords for family food-security. To enhance food security, they make use of the climate of the monsoon tropics allowing crop cultivation all year round. After the cultivation of maize in Spring, they plant rice in the rainy season with maximum temperatures of $44{ }^{\circ} \mathrm{C}$ when most of the annual rainfall of $1500 \mathrm{~mm}$ occurs (June to August). Wheat and mustard seed is planted in the cool and dry winter with minimum temperatures of $5^{\circ} \mathrm{C}$ (Anon., 1998). The declining soil nutrient is only partly replenished with manure and chemical fertilizers and, thus, results in dwindling yields and aggravated food insecurity. Pesticides are rarely used but are gaining importance with the adoption of modern rice varieties.

\section{Field conditions}

Fieldwork was conducted during several visits between December 1999 and November 2001. As the Tharu of Gobardiha have not been involved in any research or development activities so far, they were interested and eager to join exercises and discussions. Their willingness and curiosity to participate made the research an extremely pleasant task although, as noticed by Posey (1979), insects are considered as unimportant creatures not deserving much attention. As spare time was rare for farmers, efficient and time-saving methods for elicitation of insect-related knowledge were required. The research team was comprised of an environmental scientist, a Nepalese agronomist, and a female assistant familiar with both the researchers and villagers.

\section{Tools for data collection}

Several data-gathering methods were applied to gain a comprehensive picture of the farmers' knowledge system and to validate information. The research approach was based on the protocol developed by Price (2001), who combined three methods to gauge farmers' quantitative knowledge on rice field insects: Free-listing, triad testing, and consensus analysis. The present methodology further included gender analysis, focus group discussion, and successive pilesorts. In addition, the free-listing was not only analyzed by the frequency of mention but also by salience index. Finally, the present study covered not only true insects, but included the whole kiraa taxa, i.e., arthropods and other small and harmful non-arthropods. To study intra-village variation in knowledge and perception, respondents were randomly selected.

Free-listing. Free-listing is a short and convenient method to obtain information on the cultural domain of insects and their salience in the local environment as perceived by farmers. Salience can be understood as a function of biological distinctiveness (Berlin, 1992). As there is no local name for insects as taxa, we used the term kiraa that includes arthropods and anthropogenic non-arthropods defined as creatures that interact with humans. Sixteen male and fourteen female farmers aged between 10 and 73 years were asked individually to list all the kiraa they could think of. Each informant was given ten minutes to complete the task. The researcher noted down the mentioned names without commenting or interfering. Incomplete descriptors such as "green insect" were not included. At the end, the list was reviewed for unknown names or duplicates and discussed. To avoid the impact of seasonal insect occurrence and outside stimuli, the elicitation of insect names was approached in an abstract manner, i.e., without photos or specimens.

For analysis, the data was transferred to a spreadsheet. The frequency of items mentioned across the lists was calculated by counting the total number of reports of each item among the respondents. The frequency of mention, however, is a rough measure for salience, as it does not consider the item's position within the list. Items mentioned first are more salient than items mentioned last. Thus, the order of mention was considered by assigning the value 1 to the first mentioned item, 2 to the second, and so on. For the free-list salience of a given item (e.g., bug) the fre- 
quency and the order of mention were combined into a single index as done by Smith (1993). He first calculated the percentile rank across all lists measuring an item's position within the list in consideration of the total length of the list. If an item is mentioned early on, the percentile rank is higher (100 if mentioned in first position of a list of 20, 5 if mentioned last, and zero if not mentioned at all). Across all lists, the gross mean percentile rank for that item is the average of the item's percentile rankings, i.e., the sum of all percentile ranks divided by the total number of lists.

The higher the index, the earlier and more frequently the item has been mentioned. If an item were mentioned first in every list, the free-listing salience would have an index of 100. If an item occurs later in list or not at all, the index would decline towards zero. The index is a measure to find culturally important species. The free-listing data was then analyzed by gender, age, social status, and education of the respondent.

Pilesort insects. All names obtained from freelisting were written on cards. These cards were sorted by key informants that were fluent in both Nepali and Tharu language to find (i) duplicates across languages (Tharu, Nepali, Hindi), (ii) the most common kiraa name for each specimen, (iii) the total number of different kiraa listed, and to add (iv) missing names. First, multiple terms across the languages were identified and put in a horizontal line. The key informants were asked to select the term commonly used in the village. Subsequently, terms or insects unknown to the key informants were removed. Then, each name was marked according to language, recorded in a complete list that was then returned to local persons for validation.

Selected species were collected for accurate identification. By discussing insect color pictures with farmers, it was verified whether certain insects were not recognized or simply forgotten. Enlarged pictures of insects, however, were scarcely recognized although some of the presented species were commonly found in the village.

Triad test. The triad test was developed in psychology and introduced into anthropology as a structured interviewing technique to explore cognition among individuals, cultures, or sub-cultures. The individually conducted exercise serves to explore perceived similarities and dissimilarities of items. In this case, to determine whether there are subgroups, such as pests and beneficials, in the group of kiraa.

To demonstrate the procedure of the exercise, three cards showing a bicycle, a horse, and a chicken were placed in front of the informant. The informant had to select the item that was most dissimilar in the triad and give a reason for the particular choice. The exercise was then repeated with the research assistant making a different choice and thereby showing that there are numerous ways to group and that there are no wrong or right answers. For the real triad test, pictures of common kiraa ${ }^{1}$ (pests and beneficials) were discussed to make sure that the respondent recognized the pictures. The number of cards was limited to fifteen to reduce the time required for sorting to an acceptable span. The cards were presented to the informant in triads given on a form created by ANTHROPAC 4.0 software (Borgatti, 1996a). The order in which the triads were shown to informants was randomized to eliminate order-effects (Bernard, 1994). Using the balanced incomplete block design (lambda 1) (Borgatti, 1996b), letting each kiraa pair appear only once in a triad, shortened the procedure. Still, the sorting of 35 triads with fifteen items took 10 to 40 minutes.

Twenty randomly selected women and twenty male farmers of different age groups joined the exercise. As the majority of the informants was illiterate, the insects were visualized with picture cards. Under the local context, it turned out to be impossible to conduct the exercise without visual aid within a reasonable time.

Triad data was analyzed for the general concepts found among the male and female farmers. The data of individual interviews was entered for male and female respondents as a respondent-by-triad matrix in an ASCII file and unrandomized by ANTHROPAC 4.97 software. From the unrandomized data, the program computed an aggregate proximity matrix measuring similarities between items (single-link method ${ }^{2}$ ). From the aggregate proximity matrix, the program computed Johnson's hierarchical clustering resulting in a two-dimensional dendrogram of similarities between items.

For interpretation, a total of 1,400 criteria provided by the respondents was categorized into five groups, as suggested by Nazarea-Sandoval (1995a): ecological (habitat, food source, occurrence), morphological (physical appearance), physiological/behavioral (locomotion, smell), human-directed (stinging, biting, edible), and agronomic criteria (pest, beneficial, damage).

Successive pilesort. As Tharu farmers found it difficult to conceptualize insect taxonomy without visual help, basic concepts in classification were elicited by means of successive pilesorts (Boster, 1994). The successive pilesort was conducted with twenty male and twenty female farmers using selected kiraa specimen presented on cards $(n=12) .{ }^{3}$ Illiteracy forced us to work with picture cards although this is not considered optimal (Bernard, 1994; Ellen, 1993; NazareaSandoval, 1995a; Werner and Fenton, 1970). The items were gleaned from the free list that defined the kiraa domain. To find out if true insects are separated 
from other non-insect fauna, the selection of pictures went beyond insects.

The set of cards was shown to individual respondents who had to sort them into two piles. After giving the names or the criteria for these particular groupings, one of the two piles had to be further split in two, to produce three piles. Again, criteria had to be attributed. The process continued until all piles had been reduced to a single item. The criteria used were left entirely to the discretion of the respondent. For each respondent, the similarity of two insects appearing in the hierarchical clustering was indexed by the number of splits needed to separate them. The minimum possible similarity was 1 , when insects were separated at the very beginning and the maximum $\mathrm{n}-1$. The data was entered in an ASCII file to compute individual and aggregate proximities between insects with ANTHROPAC 3.2 (Borgatti, 1990). Based on individual proximities, consensus parameters such as (i) each respondent's level of knowledge, (ii) the culturally correct pilesort in form of a similarity matrix, and (iii) a chance-corrected agreement matrix were computed in a second step. The agreement matrix was submitted to multidimensional scaling, resulting in a scatterbox showing similarities between the answers. Proximity measures of similarity were computed using Euclidean distances, clustering respondents with similar perceptions together while those with different perceptions appear distant from the cluster. Multidimensional scaling of the culturally correct pilesort (similarity matrix) resulted in a scatter plot visualizing similarities among items. For interpretation, the criteria given by the respondents for grouping were listed and scored in a spread sheet as was done for the triad data. If a criterion was mentioned first, i.e., for the first split, the value 1 was assigned to it, if mentioned for the second split, the value 2 . The frequency of criteria mentioned across the lists was calculated by counting the total number of reports of each criterion. In addition, the order of mention was considered by computing a "salience index" for each criterion (see analysis triad test). Each criterion was assigned to five categories: ecological, morphological, physiological, human-directed, and agronomic criteria. The sum of all salience indexes was then calculated for each category and transformed into percentage.

Focus group discussion. Quantitative data was complemented by qualitative data obtained from focus group discussions on insect ecology and insect pest management (field and storage pests). Three to six women and men farmers were separately invited to meet in a private place for a 1-2 hour discussion. In the joint family system of the Tharu, however, it was impossible to keep gender separated or to keep discussion groups small. With male farmers, discussions were held in the Nepali language while discussions with female participants required translation into the Tharu language. The semi-structured interview followed a guideline developed from former field studies. The information was noted down on the spot, compiled in Kathmandu, reconfirmed, and complemented during consecutive trips.

Consensus analysis. Information retrieved from focus group discussions and individual interviews contain a cultural variability resulting from differences in individual intelligence, thinking patterns, understanding, and structural conditions such as sex, age, division of labor, level or hierarchy/caste, and social interaction (Caulkins and Hyatt, 1999; Ellen, 1979). Therefore, knowledge within a community is not uniform and individual answers can conflict with the common knowledge of the group. This means that the "right answer" to a question is a culturally defined concept that might again differ from the scientific answer. For researchers that are not familiar with the culture of an ethnic group, the "right answer" is, of course, unknown. The methodology of consensus analysis is based on the cultural consensus model that estimates the "culturally correct" answers and individual knowledge levels from the pattern of inter-informant agreement (Weller, 1987). It formalizes the insight that agreement often reflects shared knowledge and allows the estimation of individual knowledge levels from inter-informant agreement (Batchelder and Romney, 1988; Boster and Johnson, 1989; Romney, 1994; Weller and Romney, 1988). The consensus analysis included a randomly selected sample of twenty male and twenty female farmers. To detect gender differences in knowledge and beliefs, the interviews were conducted individually following a standard questionnaire created with ANTHROPAC 4.0. The questionnaires contained 51 questions focusing on knowledge of pest ecology, storage management, and related beliefs. The questions could be answered with "true," "not true," or "I don't know" (multiple choice test). The answers of each respondent were coded in a respondent-by-question/answer matrix. By factor analyzing the pattern of farmer-to-farmer similarities with ANTHROPAC 4.97, individual knowledge levels (cultural competencies) were calculated. The computed Eigenvalues for factors 1 and 2 indicated whether the assumption that we are dealing with one culture is correct. This is the case if the ratio of the Eigenvalue of factors 1 and 2 is more than 3 to 1 . The larger the first Eigenvalue, the stronger the support for the argument that there is a cultural consensus on correct answers and a coherent domain (Caulkins and Hyatt, 1999). The culturally correct answer was determined by weighting individual responses by the respondents' cultural competence. 


\section{Results}

The tools used to elicit farmers' perception and knowledge related to insects were very specific. This represents a methodological strength as well as a weakness, if the isolated results are not embedded in the cultural context. Therefore, we shall first look at the Tharu understanding of their role in the world, before having a detailed look at the results.

\section{The farmers' role in agriculture}

In the Tharu myth on origin, agriculture was created prior to human beings. The story goes that Shankar, the creator of the earth, felt very sad at seeing the world below covered with thatch grass. He discussed how to make better use of the land with his consort Parvati. They decided to start farming but soon encountered several problems, as farming required inputs such as irrigation, crop seeds, plow, and bullocks. Using his special powers, however, Shankar was able to solve these problems. From his long hair he let the water flow and began tilling the land by hand. As it was toilsome, he decided to use bullocks to plow. To design the plow, he again sought Parvati's advice who suggested that he look at the thirteen different parts of her body and build the plow accordingly. He tried and succeeded. ${ }^{4}$ Thereafter, he created two bullocks and did the first ritual plowing. ${ }^{5}$ After the land had been prepared, Shankar had to find crop seed. For that purpose, he engaged in deep meditation and, after twelve years, his mind showed him a forest filled with flowers. So he went there to get some flowers to sow in the tilled land. They germinated and developed into maize plants. As the maize began flowering, he took some maize panicles and sowed them. Those panicles grew into rice plants and from the sowing of rice flowers other crops emerged, such as wheat, barley, millet, buckwheat, and mustard. As the land was flat and had plenty of water, the rice thrived in abundance. During grain formation, the healthy growth and green lush of the rice field enchanted Shankar completely. For several days and nights, he remained in the field. Parvati was concerned at the absence of her husband and went to the field to investigate. There, she saw his deep fascination for the lustrous growth of the rice plants. To no avail, she tried to convince him to return home. Realizing that her efforts were useless as long the rice plants remained undamaged and attractive, she created gandhi, the rice bug, that soon infested the entire field and triggered numerous other herbivore vermin that attacked the rice plants and destroyed their beauty. Shankar became frustrated and ultimately decided to leave the rice field for home. Disheartened by the damaged crop, however, he refrained from eating and became weak. Only Parvati's promise to solve the pest problem convinced him that he must eat. Thereafter, she requested him to lay some latex from the Mahuwa tree $^{6}$ at her feet and, as he did so, the pest disappeared from the field. Only after having established farming, did the divine couple create farmers because they faced difficulties in cultivating the entire world themselves. With the growth of the farming population, however, the number of deities requiring worship increased and Shankar had no time to appease all of them. Therefore, he created village shamans as his representatives to worship the local deities. ${ }^{7}$

The story makes clear that farmers are viewed as the assistants of God and, thus, take active part in the renewal and sustenance of creation. In addition, it shows that there are two opposite forces in rice production: growth hampering and growth enhancing. Pests that threaten agricultural production and rituals that mitigate or prevent the pest damage co-exist. As such, the story narrates the natural phenomenon of ecological balance and allows farmers to play an active role. The rice bug is clearly a part of God's creation and requires control by means of ritual. It remains open, however, as to what status other insects have in God's creation and what attitude farmers have towards them.

\section{The farmers' definition of insects}

Literally, the Nepali term kiro (singular) or kiraa (plural) denotes an array of animals including insects, worms, maggots, snakes, and even tigers. The term kiraa phatyengra $\mathrm{N}$ (lit. insect-grasshoppers) standing for insects and vermin (Turner, 1997) is seldom used in the local context.

For the farmers of Gobardiha, the definition of kiraa has to be related to a wider context. Roughly, kiraa could be defined as arthropods and other small and anthropogenic creatures generally causing harm to crops, livestock, or people. Beside true insects, various kinds of ecto- and endoparasites, centipedes, earthworms, leeches, snails, slugs, amphibians, reptiles such as lizards, snakes, tortoises, alligators and crocodiles, rodents, parrots, and even monkeys are included. Most of them are considered as harmful. Edible fauna, such as aquatic snails, frogs, and some kinds of rats, are excluded from the group of kiraa in the particular context of food. Therefore, rats possess an ambivalent status: As major storage pests, they belong to kiraa, as food items they do not.

For an understanding of the term kiraa, we need to situate it in the larger domain of "living things." As not every Tharu farmer conceptualizes "living things" in the same manner, the attempt to place kiraa within the folk-taxonomic tree of the Tharu can easily lead to misleading or false results. The folk taxonomy of 
"living things" is neither stored knowledge ready to be recalled, nor a bounded, stable classification system held by a homogenous group of individuals. Elicitation methods such as successive pilesorts primarily addresses the generative or productive capacity of individuals confronted with a novel question and, thus, brings forth taxonomic structures that are seemingly inconsistent and highly dynamic. As pointed out by Ellen (1993) and Bulmer (1969), variation occurs due to the classificatory features used (habitat, morphology, behavior, utility, and ideological position). This variation stands in direct contrast to the scientific taxonomy, usage of which is explicitly restricted with the object of minimizing ambiguity. Thus, the general concepts of Tharu folk taxonomies outlined in the following paragraph provide a rough framework that is mainly the product of the elicitation process and not a vital element of Tharu thinking. It is the output of a task, which would probably never be performed without an outsider demanding it. Similar to Ellen's (1993) findings, the very idea of an abstract discussion of insect classification is alien.

"Living things" at the highest level of classification are defined as breathing organisms that feed and proliferate for survival. Some give benefit while others do not. The group contains life forms such as plants, animals/people, and kiraa. Animals are grouped based on physical features, habitat, and ecology. They are divided into legless, biped, and quadruped species. The latter is divided into furred and tailed land mammals (januaar $\mathrm{T}$ ) and amphibious or semi-aquatic fauna without fur that feeds on kiraa (e.g., alligator, frog, turtle). The second group is not named. Biped animals are winged or flying, egg-laying birds. Legless animals (e.g., fish) are aquatic, lay eggs, and have fins and gills. Finally, the species in the group of kiraa have generally no or more than four legs, and have bodies "made of pieces." As most are harmful but few also beneficial, there are functional sub-groups. The category of kiraa appears similar to Brown's notion of "wug" (a blend of worms and bugs) that includes creatures denoted by "bug" in American English (i.e., insects and other very small animals such as spiders), worms and sometimes other small creatures (Brown, 1979). In Tharu classification, however, kiraa encompasses certain species that belong to other life forms without incorporating all members of that life form. Accordingly, the kiraa group forms an intersection of species in other domains, i.e., a superordinate grouping that recognizes anthropogenic features. Harmful reptiles, birds, or fish, for instance, are counted as kiraa though they are also members of other domains (Figure 1). This "cross-cutting" is a phenomenon found in other folk biological classifications (Wyman and Bailey, 1964) and was found typical for them (Posey, 1979).
Living Things

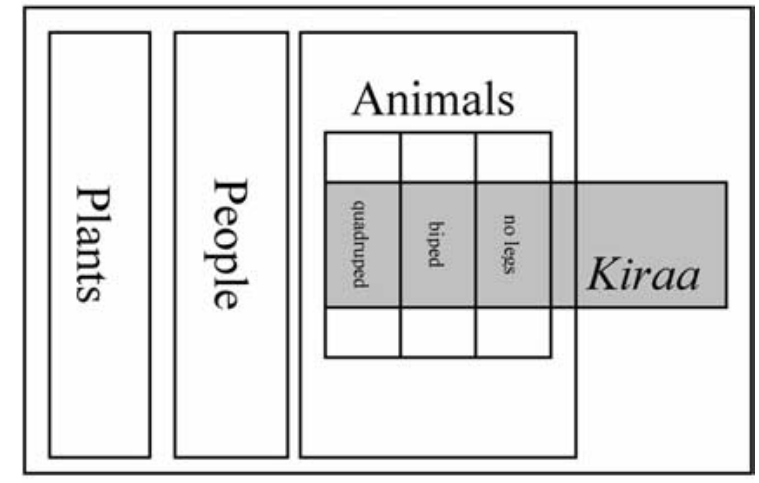

Figure 1. The Tharu understanding of "living things."

Interestingly, snakes are part of the kiraa group and do not occur as a independent life form as it is frequently the case in folk zoological taxonomy (Brown, 1979). Humans are sometimes grouped with biped species but often taken as a separate group as they have reason and intellect to manipulate other species (e.g., crops and livestock).

Apart from this morphological-ecological classification, Tharu farmers group "living things" in a valuebased hierarchy ranking human highest (they can control other organisms) followed by plants, in particular crops (due to the mutual dependence of farmers and crops), animals and kiraa at the lower end of the hierarchy.

Grouping insects together with other arthropods and other small animals has been observed in many folk classifications. In the ethnozoological classification of the Fore of Highland New Guinea, insects, spiders, and worms are grouped as kabágina (Diamond, 1966). The Hanunóo of the Philippines refer to insects, spiders, and most other very small animals as 'iyay (Conklin, 1954 in: Berlin, 1992) and the category maja of the Kayapó Indians of Central Brazil corresponds one-to-one with the scientific category of Phylum Arthropoda as it includes insects, scorpions, spiders, ticks, centipedes, millipedes, crayfish, and pseudoscorpiones (Posey, 1981). The Ndumba of New Guinea, however, separate insects and arachnids (tovendi) from reptiles, eels, centipedes, and worms (kaapa'raara) (Hays, 1983 in: Berlin, 1992) while the Nuaulu of Seram have no collective term for insects but directly name different orders and families (Ellen, 1993).

In Tharu culture, kiraa are generally considered as harmful and as a mistake in God's creation. They either ruin the harvest or affect livestock and people by stinging, biting, and annoying them. Such judgement is, however, often not backed up by personal experience. ${ }^{8}$ Holding insects in such low regard is not unusual in traditional cultures. The 
Table 1. Useful and beneficial kiraa as perceived by the Tharu farmers of Gobardiha $(n=24)$.

\begin{tabular}{|c|c|}
\hline Benefit & Kiraa name \\
\hline Pollination & $\begin{array}{l}\text { Bee, Bumblebee, Butterfly, Sphinx moth, } \\
\text { Dragonfly, Housefly }\end{array}$ \\
\hline $\begin{array}{l}\text { Soil fertility } \\
\& \text { Sanitation }\end{array}$ & $\begin{array}{l}\text { Earthworm, Crab, Dung Beetle, White } \\
\text { Grub }\end{array}$ \\
\hline Nutrition & Honey bee, edible aquatic snail \\
\hline Medicine & $\begin{array}{l}\text { Honey bee }^{\mathrm{a}} \text {, Wild bee } \\
\text { Firefly }{ }^{\mathrm{d}} \text {, Whirligig Beetle } \\
\text {, White } \text { Grub }^{\mathrm{e}} \text {, Spider } \\
\text { Crab }^{\mathrm{f}} \text {, Tortoise }\end{array}$ \\
\hline Predation & $\begin{array}{l}\text { Red Ant }{ }^{\mathrm{j}} \text {, Ladybird Beetle }{ }^{\mathrm{k}} \text {, Tiger Beetle, } \\
\text { Dragonfly, Field Cricket }^{\mathrm{l}} \text {, Spider }{ }^{\mathrm{m}} \text {, Wall } \\
\text { Lizard }^{\mathrm{n}} \text {, Garden Lizard, Frog, Bat }\end{array}$ \\
\hline $\begin{array}{l}\text { Spiritual use, } \\
\text { Forecast }\end{array}$ & $\begin{array}{l}\text { Praying Mantis }{ }^{\mathrm{o}}, \text { Midge }^{\mathrm{p}}, \text { Spider }^{\mathrm{q}}, \text { Crab }^{\mathrm{r}} \text {, } \\
\text { Frog }^{\mathrm{s}}, \text { Mouse }^{\mathrm{t}}\end{array}$ \\
\hline Others & White Grub ${ }^{\mathrm{u}}$, Spider $^{\mathrm{v}}$ \\
\hline
\end{tabular}

Notes: ${ }^{\mathrm{a}}$ Honey: Antidote to alcohol poisoning and general tonic; ${ }^{\mathrm{b}}$ Smoke of wax repels foot and mouth disease; ${ }^{\mathrm{c}}$ Necklace or oral intake against fever; ${ }^{\mathrm{d}}$ Treatment against night blindness; e Oral intake of dried grubs to cure sprains and broken bones; ${ }^{\mathrm{f}}$ External application of cobweb suppresses boils; ${ }^{\mathrm{g}}$ Oral intake of aquatic species against tuberculosis and swellings; ${ }^{\text {h Soup as }}$ tonic, enhances lactation; ${ }^{i}$ Meat against asthma; ${ }^{j}$ Fruit pests; ${ }^{\mathrm{k}}$ Drives off/kills rice bugs; ${ }^{1}$ Aphids; ${ }^{\mathrm{m}}$ Flies and mosquitoes; ${ }^{\mathrm{n}}$ Mosquitoes, houseflies, bed bugs, and cucumber pests; ${ }^{\circ}$ Tied at the neck and hung outside, the moving legs will trigger

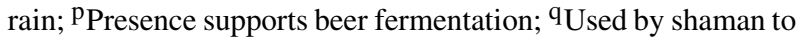
drive away ghosts; good omen as cobwebs absorb 'things' such as grain soul (food security); ${ }^{\mathrm{r}}$ Ritual object; ${ }^{\mathrm{s}}$ Croaking forecasts rainfall; ${ }^{t}$ High population signals high yields and conserves grain soul; ${ }^{\mathrm{u}}$ Fish bait; ${ }^{\mathrm{v}}$ Cobwebs strengthen house structure.

Northern Iroquoians, for instance, universally consider insects as evil, a constituent of evilness, or certainly, non-beneficial (Starna et al., 1984). Lumping insects together in the category of "small and harmful creatures" has also been observed with Indonesian (Settle et al., 1996) and Honduran farmers (Bentley, 1992: 93).

Though the Nepali term kiraa is negatively stigmatized, not all items in the domain are conclusively classified as harmful. The kiraa shown in Table 1 represent the collective knowledge of 24 farmers who were requested to list beneficial/useful insects. Most respondents listed three to five species only. Although few predatory insects have been observed, the concept of biological pest control is not clear. Predatory insects are first perceived as harmful. Giving a second thought, some are found to provide certain benefits.

Some species are attributed to both categories, beneficial and harmful, depending on the context. The praying mantis, for instance, is not recognized as a predator but estimated for its rain-making qualities and feared for its alleged habit of tearing people's eyes out. The latter is reflected in its name aakh phoruwa, literally meaning "eye breaker." This fear dominates farmers' perception although most of them know that it is harmless to crops. Similarly, spiders are perceived as beneficial as the presence of cobwebs in old houses is interpreted as a structural reinforcement stabilizing the house. Nevertheless, the spider's dirt and cobwebs hampering plant-growth again neutralize the spider's credit and make it harmful.

Language provides further evidence for the absence of a clear concept of pests and beneficials as no Nepali or Tharu word is assigned to these two terms. Missing a proper noun, pests are described as "damage-causing kiraa" (noksan/bigaar karna kiraa T) and "being harmful" (hanikarak chaa N). Likewise, "benefitgiving kiraa" (phaidaa dena kiraa $\mathrm{T}$ ) refers to beneficials, though farmers hardly know what kind of benefit to expect. Specific names of pest insects found in literature (APROSC, 1991; Neupane, 1989; Thapa, 1997: 98, 2000) are direct translations from English terms but rarely known or used by local people.

\section{The farmers' knowledge of insects}

Quantitative knowledge (free-listing). The listing of kiraa revealed 120 vernacular names denoting 119 different species ${ }^{9}$ (Table 2). As a striking fact, almost exclusively the Tharu names were used while the only multiple-named kiraa was the tortoise. Free-listing would hardly reveal more than 125 species, even if more than thirty respondents were included in the sample (Figure 2). Among the 119 kiraa mentioned, $67 \%$ (80) belong to real insects, $8 \%$ (10) to non-insect arthropods (e.g., spider, centipede), and $24 \%$ (28) to non-arthropods (e.g., snake, rat). One name (1\%) remained unidentified.

The smallest number of recounted names was 10 (informant no. 4), while the most was 32 (informant no. 22). The average number of names mentioned (21.1) was equal for males and females. The increase of knowledge on kiraa names with age was not significant $(P=0.64)$, indicating that this knowledge is mainly acquired at an age below ten years (Figure 3 ).

No correlation was found between the number of kiraa names and years of schooling. The notion that knowledge of kiraa names is independent of formal education is supported by the fact that women with average schooling of 1.4 years knew as much as men with average schooling of 3.9 years.

Farmers' status (rich, subsistence, or laborers) had no detectable impact on quantitative knowledge. The assumption that low socioeconomic household members have more knowledge of insects as they spend 


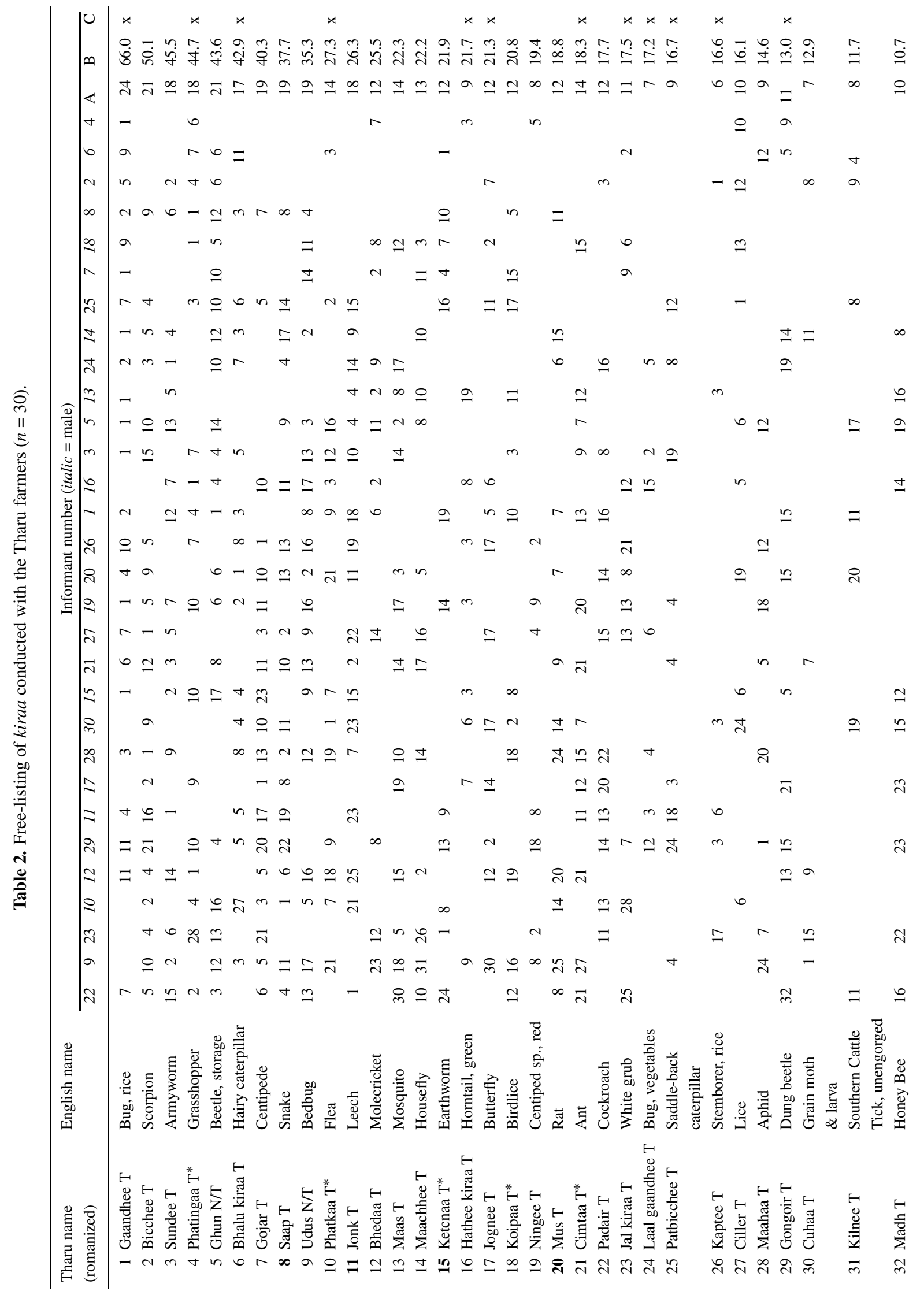




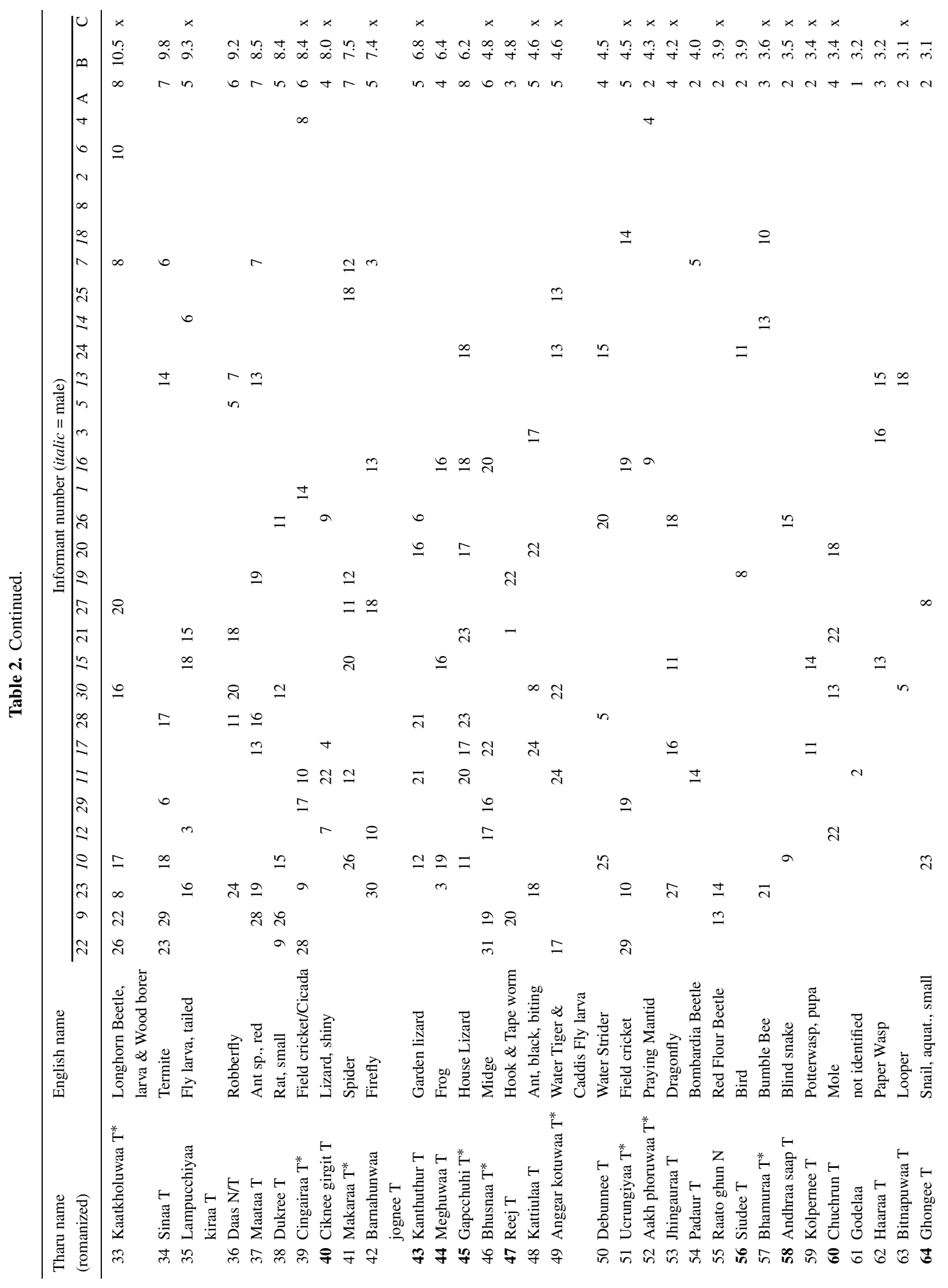




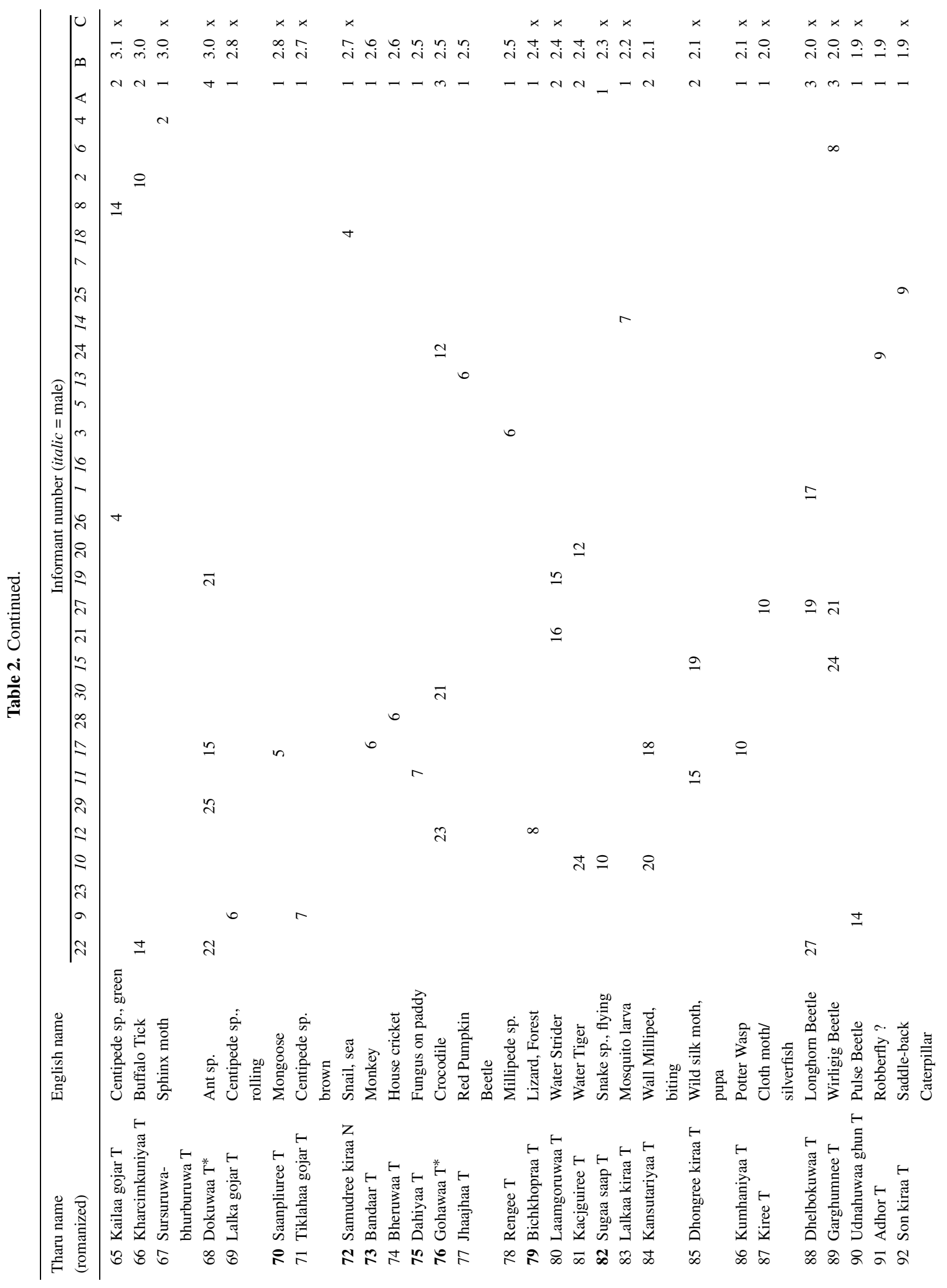


THARU FARMERS' PERCEPTION AND KNOWLEDGE OF INSECTS

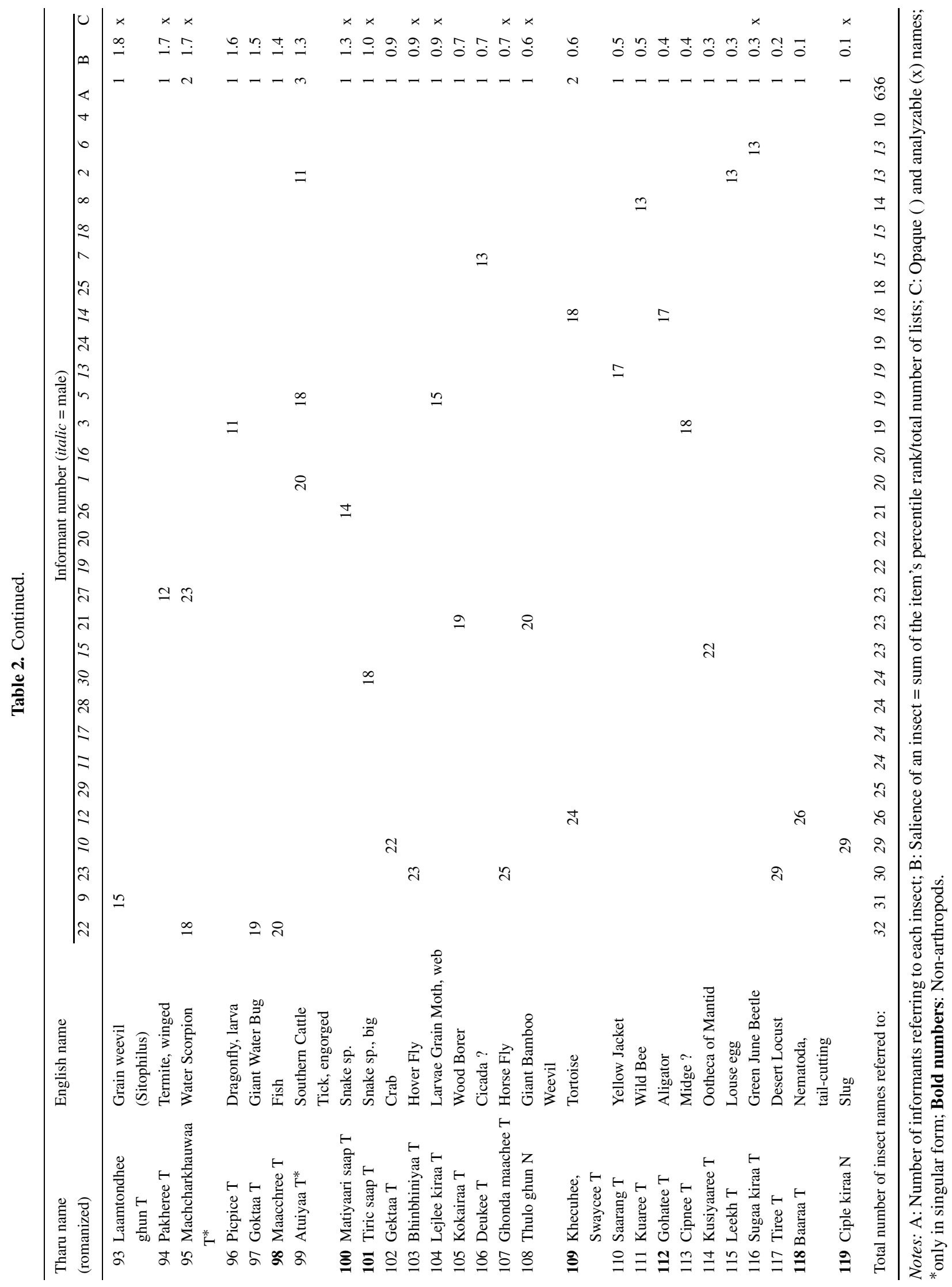




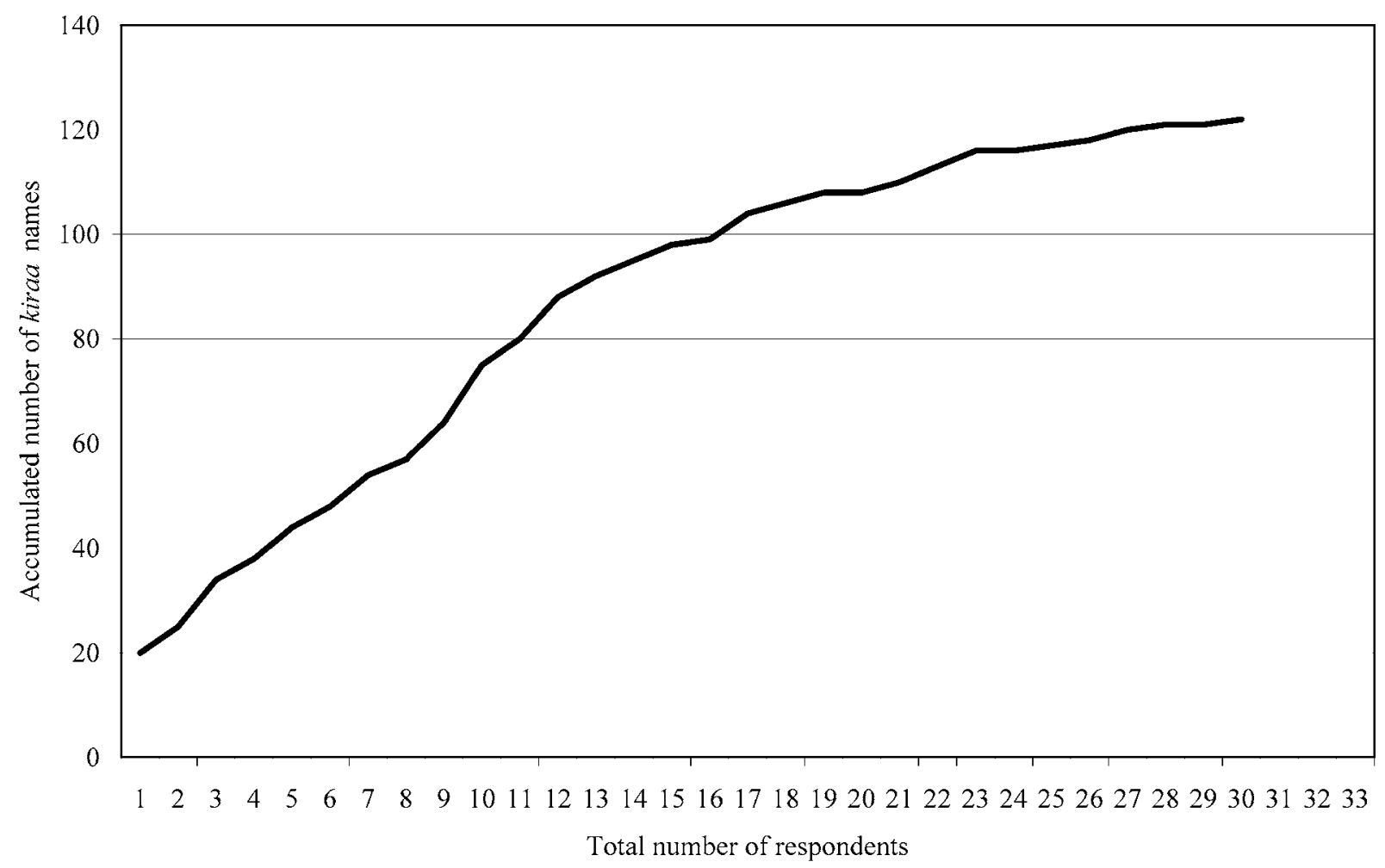

Figure 2. Accumulated number of kiraa referred to by respondents during free-listing $(n=30)$.

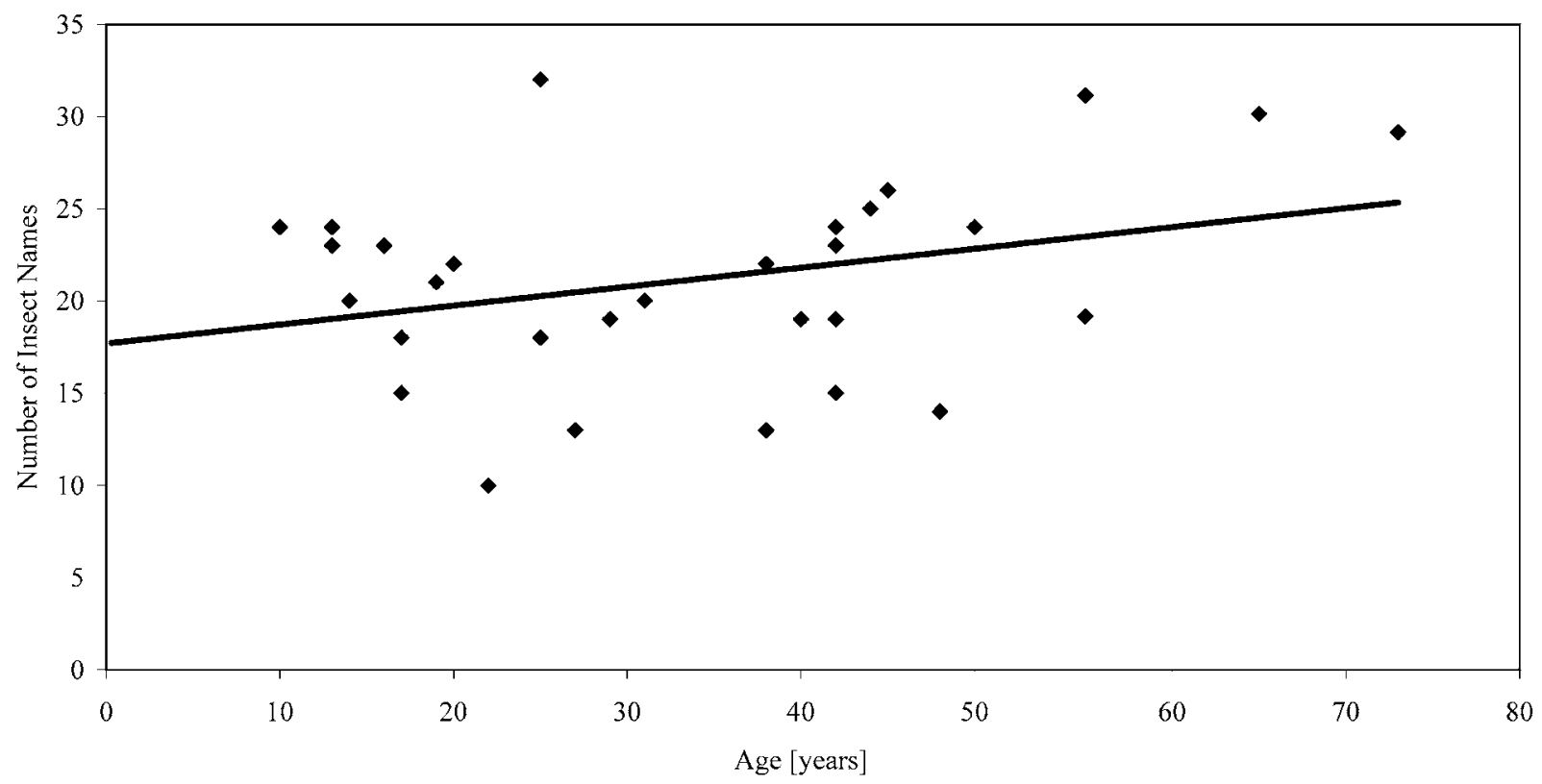

Figure 3. Number of kiraa names referred to by individual farmers during free-listing vs. age $(n=30)$. 
more time in the fields as hired laborers, as observed by Nazarea-Sandoval (1995b) in the Philippines, is not supported by the present data. One explanation might be that the socioeconomic stratification within the Tharu community is far less distinct than in the Filipino case.

Reviewing the frequency of reference and salience index calculated from the free-listing showed that culturally important and easily observed species, i.e., serious pests and poisonous species, are prevalent in farmers' minds. The frequency of reference (column A) was highest for the rice bug (24 out of 30 informants), second highest for the scorpion and coleopteran storage pests (21), and third for centipede, snake, and bedbug (all 19). Thereafter followed culturally unimportant, but easily observed, species and towards the end numerous species difficult to observe, whereas some are culturally important and some are not. This shows that salience is strongly related to the specimen's anthropogenic impact, size, and abundance, as has been observed among Honduran farmers (Bentley et al., 1994). Similar to the observation of Brown (1990), highly salient kiraa names are mainly labeled with unitary and short names (e.g., gaandhee) while those of lower salience more often have binomial names (e.g., kailaa gojar).

The list order differs slightly when sorted by salience index (SI) (column B). Whereas rice bug (SI 66) and scorpion (SI 50) keep their positions as the most salient kiraa, the army worm (SI 46) and the grasshopper (SI 45) occupy the third and fourth positions on the list. Both insects are abundant and considered as plant pests.

The number of insect terms recalled by individuals seems small. We must bear in mind, however, that listing of names in the course of a free-listing exercise is not the same as knowledge of names (respondents know more than they recall); and knowledge of names is again different from knowledge about kiraa. Neither does naming insects necessarily indicate an ability to identify them accurately and consistently.

Qualitative knowledge (free-listing). The freelisting reflected the high cultural importance of livestock and fishing in the Tharu livelihood. As poultry, goats, pigs, buffalo, and oxen are found in most homesteads, the Tharu have acquired detailed knowledge of livestock parasites. The listing revealed 13 different ecto- and endoparasites. The bed bug ( udus T/N) was mentioned most often, followed by the mosquito (maas T), flea (phatkaa T), bird lice (koipaa T), cattle ticks (kilnee, atuiyaa, and kharcimkuniyaa T, Ixodidae), and worms. Kilnee and atuiyaa denote unengorged (small) and engorged (large) specimens of the two genera Haemaphysalis and Boophilus that appear superficially similar when one looks at unengorged
Table 3. Caterpillar species identified by Tharu farmers.

\begin{tabular}{lll}
\hline Tharu Name & English/Scientific name & Gloss \\
\hline Bhalu kiraa & $\begin{array}{l}\text { Hairy caterpillar } \\
\text { (many genera) }\end{array}$ & Bear insect \\
Paat bicchee & $\begin{array}{l}\text { Saddle-back caterpillar, } \\
\text { white }\end{array}$ & Leaf scorpion \\
Son kiraa & Saddle-back caterpillar & Golden insect \\
Sundee & $\begin{array}{l}\text { Army worm (Helicoverpa } \\
\text { armigera Hubner) }\end{array}$ & - \\
Bitnapuwaa & $\begin{array}{l}\text { Looper (Geometridae } \\
\text { and other genera) }\end{array}$ & Measurer \\
$\begin{array}{l}\text { Haathee } \\
\text { kiraa }\end{array}$ & $\begin{array}{l}\text { Green Horntail } \\
\text { (Sphingidae) }\end{array}$ & Elephant insect \\
Kaptee & $\begin{array}{l}\text { Stemborer (Sesamia } \\
\text { inferens, Noctuidae) }\end{array}$ & The cunning one \\
Lejlee kiraa & $\begin{array}{l}\text { Angouois Grain Moth } \\
\text { larva (Gelechiidae) }\end{array}$ & Webbing insect \\
\hline
\end{tabular}

specimens or engorged females. Kharcimkuniyaa denotes the red males of Hyalomma anatolicum (J.E. Keirans, personal communication).

Unique was the vast knowledge on aquatic insects. Not less than 16 aquatic insects, fishes, frogs and reptiles were recalled. With the exception of the sphinx moth (sursuruwa-bhurburuwa T), butterflies and moths were of very little interest to the Tharu and, thus, collectively named as jogni. T. Lepidopteran larvae are sorted more carefully as they attack crops and often have hair that causes allergic skin reactions (Table 3). As noted by Hunn (1982), this is not unusual for folk classifications. For farmers, the larvae are noteworthy while the adults, specialized for mating, are not.

Among the listed Hymenopterans we find ants, bees, bumblebees, and wasps. The group of bees and wasps contains only seven species with a relatively low salience index (Table 4). This is far less than the data collected from other Nepalese communities ${ }^{10}$ or other countries (Bentley and Rodríguez, 2001; Posey, 1979). Unlike the Raji, a semi-nomadic group of the Terai specializing in the collection of honey of wild bees (Valli, 1998), the Tharu are least interested in beekeeping or honey-hunting. Nevertheless, they appreciate honey bees, bumble bees, and carpenter bees as pollinators. The process of pollination, however, was hardly conceptualized. ${ }^{11}$ Solitary wasps were scarcely known and named. Ants, in contrast, were classified on the specific level, although many of them were not recalled during free-listing but only after further probing (Table 5). 
Table 4. Hymenopteran species identified by Tharu farmers.

\begin{tabular}{lll}
\hline Tharu Name & English/Scientific name & Gloss \\
\hline Bhamuraa & $\begin{array}{l}\text { Bumble bee (Bombidae) } \\
\text { Madh }\end{array}$ & $\begin{array}{l}\text { Strolling around } \\
\text { Apidae) }\end{array}$ \\
Kuaree & $\begin{array}{l}\text { Wild bee (wild form of } \\
\text { Apis cerana) }\end{array}$ & - \\
Haaraa & Paper wasp (Vespidae) & - \\
Saarang & Yellow Jacket (Vespidae) & - \\
Kumhaniyaa & $\begin{array}{l}\text { Potter wasp (Sphecidae, } \\
\text { Eumenidae, Scoliidae) }\end{array}$ & Female potter \\
Kolpernee & Potter wasp larva & $\begin{array}{l}\text { Moving like } \\
\text { oil-press }\end{array}$ \\
\hline
\end{tabular}

Table 5. Ant species identified by Tharu farmers.

\begin{tabular}{|c|c|c|}
\hline Tharu Name & $\begin{array}{l}\text { Scientific } \\
\text { name }\end{array}$ & Gloss \\
\hline Cimtaa & $\begin{array}{l}\text { All } \\
\text { Formicidae }\end{array}$ & 'Tweezer-like' \\
\hline Sendhauree c. & $\begin{array}{l}\text { Monomorium } \\
\text { destructor } \\
\text { Jerdon }\end{array}$ & $\begin{array}{l}\text { Red, small, smelling, } \\
\text { household pest, attracted } \\
\text { to sweets }\end{array}$ \\
\hline Maataa & $\begin{array}{l}\text { Oecophylla } \\
\text { smaragdina } \\
\text { Fab. }\end{array}$ & $\begin{array}{l}\text { Arboreal weaver ant, } \\
\text { predatory, sour body fluid }\end{array}$ \\
\hline $\begin{array}{l}\text { Maataa } \\
\text { cimtaa }\end{array}$ & Not identified & $\begin{array}{l}\text { 'Automatically emerging' } \\
\text { from the ground, red }\end{array}$ \\
\hline Maha cimtaa & Plagiolepis sp. & $\begin{array}{l}\text { 'Stinking ant', small, } \\
\text { predatory on mites, etc. }\end{array}$ \\
\hline Kattiulaa & $\begin{array}{l}\text { Sima } \\
\text { rufonigra } \\
\text { Jerdon }\end{array}$ & $\begin{array}{l}\text { 'Wood-dwelling', black, } \\
\text { wasp-like sting }\end{array}$ \\
\hline Dokuwaa & $\begin{array}{l}\text { Camponotus } \\
\text { dolendus Forel }\end{array}$ & $\begin{array}{l}\text { 'Bullying others', feeding } \\
\text { on honeydew excreta of } \\
\text { Homoptera }\end{array}$ \\
\hline Cipniyaa & Not identified & $\begin{array}{l}\text { Black, poisonous, } \\
\text { 'pinching' }\end{array}$ \\
\hline Gaandaulree c. & $\begin{array}{l}\text { Crematogaster } \\
\text { spp. near } \\
\text { dorhni Forel }\end{array}$ & $\begin{array}{l}\text { 'Walking with raised } \\
\text { abdomen', black, } \\
\text { dependant on Homoptera }\end{array}$ \\
\hline Bishkhahuwa & $\begin{array}{l}\text { Pachycondyla } \\
\text { rufipes Jerdon }\end{array}$ & $\begin{array}{l}\text { 'Poisonous', black, one } \\
\text { of the largest oriental } \\
\text { stinging ants }\end{array}$ \\
\hline Deukee & Specific & Red, on chilli \\
\hline
\end{tabular}

\section{Semantics (pilesorts)}

The pilesort following the free-listing revealed 173 kiraa names for 141 different species (151 Tharu, 34 Nepali, and 4 Hindi names). It is a striking fact that Tharu farmers do not use English and hardly any Nepali kiraa names, although they know some. This is strong evidence that modern knowledge has so far hardly penetrated their isolated knowledge system.

A review of the etymology of Tharu kiraa names resulted in 98 opaque names and 91 names coined by the kiraa's attributes. Opaque names generally were short and occurred earlier in the free-listing. This indicates that these names are easily memorized due to high salience and, thus, do not need a self-explanatory nomenclature. The appearance is an important factor in naming but by no means the only one. Of the 91 linguistically analyzable names, $46.2 \%$ (42) are based on morphological characteristics, $30.8 \%$ (28) relate to behavior or locomotion, $8.8 \%$ (8) to the habitat or host, $7.7 \%$ (7) to human impact, and 6.6\% (6) were "echoic words" designating sound-producing insects (Table 6). This finding supports Berlin's (1992) observation that salient morphological and behavioral features are often encoded in the ethnobiological names to facilitate learning, memorizing, and use. According to Hunn (1982), however, only useful insects are recognized and named. It is evident that poisonous caterpillars and plant pests are by no means useful in the narrow sense of the word. In the Tharu understanding of kiraa, hardly any would be called useful. "Useful" in Hunn's sense must be interpreted as "useful to know as they are a potential danger to people, livestock, or plants," or, as proposed by Bentley and Rodriguez (2001), as "culturally important." Bulmer (1969) relates naming to economic and cultural significance, salience, and impact on animals, plants, minerals and places, which are functionally significant or salient. The list of analyzable names makes clear, however, that "usefulness" alone does not explain all the naming. For some species, there is no other explanation why they should be named if it were not for their beauty or conspicuousness. The blow fly, the green June beetle, or the sphinx moth are named for their appearance or behavior and not for their cultural importance. Thus, for naming, kiraa not only need to be of higher perceptible relevance for the farmer ("useful"), but also biologically distinct.

As an interesting fact, some Tharu kiraa names are only known in either singular or plural form. The praying mantis occurs only in singular form implying that it is a solitary species. Similarly, the grasshopper, ant, flea, mole cricket, cicada, spider, bumblebee, and a few other species appear in singular form only. The 
Table 6. Etymology of analyzable kiraa names.

\begin{tabular}{|c|c|c|c|c|}
\hline Tharu name (romanized) & English name & Other names & Gloss & Explanation \\
\hline \multicolumn{5}{|c|}{ Morphological features/physical appearance } \\
\hline 1 Andhraa saap $\mathrm{T}$ & Blind snake & & Andhraa $=$ blind & The 'blind snake' \\
\hline 2 Barkaa machiyaa $\mathrm{T}$ & Blue Bottle Fly & & Barkaa = large & The 'big fly' \\
\hline 3 Barnahunwaa jognee $\mathrm{T}$ & Firefly & Jognee $\mathrm{T}$ & Baranhunwaa $=$ burns like fire & Insect burning like fire \\
\hline 4 Bhainse gandhee $\mathrm{N}$ & Ladybird Beetle & & $\begin{array}{l}\text { Bhaisee }=\text { buffalo, } \\
\text { gandhee }=\text { stink bug }\end{array}$ & $\begin{array}{l}\text { A 'stink bug' strong like buffalo } \\
\text { attacking other insects }\end{array}$ \\
\hline 5 Bhalu kiraa & Hairy caterpillar & Jhusle kiraa $\mathrm{N}$ & Bhalu = bear & Hairy like bear \\
\hline 6 Bhurburuwa-sursuruwaa $\mathrm{T}$ & Sphinx moth & & Surh $=$ trunk & Insect with trunk \\
\hline 7 Bhusnaa $\mathrm{T}$ & Midge sp. & Bhusuna N & Bhus $=$ dust $/$ husk & Small like dust \\
\hline 8 Bicchiaak gotiyaar & Earwig & & $\begin{array}{l}\text { Bicchi }=\text { scorpion, } \\
\text { gotiyaar = clan }\end{array}$ & Belonging to the scorpion clan \\
\hline 9 Chotkee/Saano ghonghee & Snail, small & & $\begin{array}{l}\text { Chotkee/saano = small, } \\
\text { ghonghee = small snail }\end{array}$ & The very small snail \\
\hline 10 Chotkee phatingaa $\mathrm{T}$ & Leafhopper & & $\begin{array}{l}\text { Chotkee = small } \\
\text { phatingaa = grasshopper }\end{array}$ & The small grasshopper \\
\hline 11 Chuchrun $\mathrm{T}$ & Mole/Musk rat & & Chucha $=$ long snout & Having a pointed snout \\
\hline 12 Ciknee girgit $\mathrm{T}$ & Lizard sp. & & Ciknee $=$ shiny, silky & The 'shiny lizard' \\
\hline 13 Cimtaa T & Ant & Kamilaa N & Cimtaa $=$ tweezer & The 'tweezer' (pinching people) \\
\hline 14 Ciple kiraa N & Slug & & Ciple = slippery, slimy & The 'slimy insect' \\
\hline 15 Debunnee/Dibunnee $\mathrm{T}$ & Water Strider & & Debunnee $=$ small $\&$ round & $\begin{array}{l}\text { Also said to malnourished children with } \\
\text { big bellies }\end{array}$ \\
\hline 16 Dhurhwaail T & Mould & Dusee N & Dhura $=$ dust & Something 'dust-like' \\
\hline 17 Dokuwaa $\mathrm{T}$ & Ant sp. & & $\begin{array}{l}\text { Doku }=\text { basket carried } \\
\text { on the back }\end{array}$ & Looks like carrying bamboo basket \\
\hline 18 Gengtahuwaa bicchee $\mathrm{T}$ & Black scorpion & & Gengtahuwaa $=\mathrm{crab}$ & The 'crab-like scorpion' \\
\hline 19 Gojar T & Centipede sp. & & Gojar $=$ several legs & The one with many legs \\
\hline 20 Haathi kiraa & Horntail & & Haathi = elephant & Fat like an elephant \\
\hline 21 Jognee & Butterfly & Putali N & Jognee $=$ colorful $/$ blinking & Flight appears like blinking \\
\hline 22 Kaila gojaar $\mathrm{T}$ & Centipede sp. & & $\begin{array}{l}\text { Kaail }=\text { green }, \\
\text { kaila }=\text { the green one }\end{array}$ & The green centipede \\
\hline 23 Kaila gaandhee $\mathrm{T}$ & Leafhopper & & $\begin{array}{l}\text { Kaail }=\text { green }, \\
\text { kaila }=\text { the green one }\end{array}$ & The green 'bug' \\
\hline 24 Kauwak pucpuccee $\mathrm{T}$ & Spittle Bug & & $\begin{array}{l}\text { Kauwak = crow, } \\
\text { pucpuccee }=\text { spittle }\end{array}$ & Covered with spittle \\
\hline 25 Kiri & $\begin{array}{l}\text { Paper \& cloth } \\
\text { feeding insects }\end{array}$ & & Kiri $=$ small insects & Small and mostly invisible creatures \\
\hline 26 Kuiree bicchee $\mathrm{T}$ & Brown scorpion & & Kuiree $=$ brown & The brown scorpion \\
\hline 27 Lalka gojar T & Centipede sp. & & Laal $=$ red & The red centipede \\
\hline 28 Laamgoruwaa $\mathrm{T}$ & Water Strider & & $\begin{array}{l}\text { Laam = long, } \\
\text { goruwaa = having legs }\end{array}$ & The 'long-legged' \\
\hline 29 Laampuchiya kiraa $\mathrm{T}$ & Fly larvae & & $\begin{array}{l}\text { Laamo }=\text { long, } \\
\text { puchee }=\text { tail }\end{array}$ & The 'long-tailed insect' \\
\hline 30 Laamtodhi ghun $\mathrm{T}$ & Pulse weevil & & $\begin{array}{l}\text { Laamo } \mathrm{N}=\text { long, } \\
\text { todhi = snout }\end{array}$ & The 'long snouted weevil' \\
\hline 31 Lalka kiraa $\mathrm{T}$ & Mosquito larva & & $\begin{aligned} \text { Lalka } & =\text { red } \\
\text { kiraa } & =\text { insect }\end{aligned}$ & Reddish looking? \\
\hline $32 \mathrm{Laal} / \mathrm{Lalka}$ gaandhee $\mathrm{H} / \mathrm{T}$ & Red bugs & & $\begin{aligned} \text { Laal/lalka } & =\text { red } \\
\text { gaandhee } & =\text { stink bug }\end{aligned}$ & Red (stink) bug \\
\hline 33 Matiyaaree saap T & Snake sp. & & Maato = earth, soil & The 'earthern-color, soil-dwelling snake' \\
\hline 34 Pakheri T & Winged termite & & Pakheta $\mathrm{N}=$ wings & The 'winged one' \\
\hline 35 Sinduriya & Red Mite & & Sindur $=$ red lead powder & Red and small like lead powder \\
\hline 36 Siuree N & Bird (rice pest) & & Siuro $=$ forehead & The 'one having a (red) forehead' \\
\hline
\end{tabular}


Table 6. Continued.

\begin{tabular}{|c|c|c|c|c|}
\hline Tharu name (romanized) & English name & Other names & Gloss & Explanation \\
\hline 37 Son kiraa $\mathrm{T}$ & $\begin{array}{l}\text { Caterpillar with } \\
\text { golden back }\end{array}$ & & Son $=$ gold & Shiny like gold \\
\hline 38 Son kiraa $\mathrm{T}$ & Golden Tortoise Beetle & & Son $=$ gold & Shiny like gold \\
\hline 39 Suggaa kiraa T/N & Green June Beetle & & Sugga $=$ green parrot & Green like a parrot \\
\hline 40 Suggaa saap T & Flying snake & & Sugga $=$ green parrot & Green like a parrot \\
\hline 41 Thulo ghun $\mathrm{N}$ & Wood/Bamboo borer & & $\begin{aligned} \text { Thulo } & =\text { large } \\
\text { ghun } & =\text { weevil }\end{aligned}$ & Large weevil \\
\hline 42 Ujar kiraa $\mathrm{T}$ & Grain moth larva & & Ujar = white & White larva \\
\hline \multicolumn{5}{|l|}{ Behavior/locomotion } \\
\hline 1 Bhenda $\mathrm{T}$ & Molecricket & Kickicyaa T & Bhenda $=$ digging action & Digging soil and bunds \\
\hline 2 Bhinbhiniyaa $\mathrm{T}$ & Hover fly & & Bhin $=$ circle around & Flying in circles \\
\hline 3 Bitnapuwaa $\mathrm{T}$ & Looper & & $\begin{array}{l}\text { Bitna }=\text { to measure by } \\
\text { spreading fingers }\end{array}$ & Moves like measuring something \\
\hline 4 Dehkutni makara $\mathrm{T}$ & Harvest Man & & Dehkutni = foot mill & Torn-out legs jerk like local foot mill \\
\hline 5 Dhelbokuwaa $\mathrm{T}$ & Longhorn Beetle & & $\begin{array}{l}\text { Dhela bokne = carrying } \\
\text { piece of soil }\end{array}$ & $\begin{array}{l}\text { Holds mud clods when pulled away } \\
\text { or lifted up }\end{array}$ \\
\hline $\begin{array}{l}6 \text { Garghumnee, } \\
\text { Ghumne kiraa T }\end{array}$ & Water Strider & & $\begin{array}{l}\text { Gar ghumne = rotating from } \\
\text { the base }\end{array}$ & flying in circles over the water surface \\
\hline 7 Goktaa, Gogtaa T & Watertiger & & Goktaa $=$ very slowly moving & Moving like a dumb \\
\hline 8 Ghonghaa $\mathrm{T}$ & Edible Snail, big & & $?$ & Slowly moving/stationnary \\
\hline 9 Gongair $\mathrm{T}$ & Dung beetle & Gobre kiraa $\mathrm{N}$ & $\begin{array}{l}\text { Gongair }=\text { blind, clumsy } \\
\text { movement }\end{array}$ & Blind/foolish insect \\
\hline 10 Jal kiraa $T$ & White Grub & Khumbre kiraa $\mathrm{N}$ & $\mathrm{Jal}=$ water & Used as fish bait in water \\
\hline 11 Kaanhaa kansaa & Grasshopper sp. & & $\begin{aligned} & \text { Kaanhaa }=\text { Krishna } \\
& \text { Kansaa }=\text { Krishna's uncle } \\
& \text { to be killed by Krishna }\end{aligned}$ & $\begin{array}{l}\text { Occurs in Aug/Sep on Krishna } \\
\text { Janmastami day }\end{array}$ \\
\hline 12 Kanthuthur T & Garden Lizard & & $\begin{array}{l}\text { Kan = alert, } \\
\text { thuthur = mouth }(\text { head })\end{array}$ & Alert looking reptile \\
\hline 13 Kaptee T & Stemborer, rice & Gabaaro N & Kaptee $=$ cunning & Hiding \\
\hline 14 Kolperni $\mathrm{T}$ & Potter Wasp, pupa & & $\begin{array}{l}\text { Kol }=\text { oil press, } \\
\text { perni }=\text { turning }\end{array}$ & Moving like oil-extractor \\
\hline 15 Kumhaniyaa $\mathrm{T}$ & Potter Wasp & & The 'female potter' & Making nests of clay \\
\hline 16 Lejlee kiraa $\mathrm{T}$ & Larvae of Grain Moth & & Lejyal = webbing & $\begin{array}{l}\text { Produces webbings making grain } \\
\text { stick together }\end{array}$ \\
\hline 17 Maataa $\mathrm{T}$ & Ant sp. & & Mata $=$ raised up & ant with abdomen standing up \\
\hline 18 Machcharkhouwaa $\mathrm{T}$ & Water Scorpion & & $\begin{aligned} \text { Machchar } & =\text { fish } \\
\text { khouwaa } & =\text { eater }\end{aligned}$ & Predator on fish \\
\hline 19 Maachik baagh T & Wolf Spider & & $\begin{array}{l}\text { Maachik = fly } \\
\text { baagh }=\text { tiger }\end{array}$ & Actively hunting flies \\
\hline 20 Padair $\mathrm{T}$ & Bombardia Beetle & & Padair $=$ emitting gas & The 'gas emitting insect' \\
\hline 21 Phatingaa $\mathrm{T}$ & Grasshopper & Phatyengraa $\mathrm{N}$ & Patarigah sk. $=$ flying & The 'flying/jumping insect' \\
\hline 22 Phatkaa T & Flea & Upiyaa $\mathrm{N}$ & Phatak T = jumping & The 'jumping insect' \\
\hline 23 Sapliuraa $T$ & Mongoose & & $\begin{array}{l}\text { Sap }=\text { snake, } \\
\text { liuraa = eating }\end{array}$ & The 'snake swallower' \\
\hline 24 & Tiger Beetle & Sikaree kiraa N & Sikaree $=$ hunter & The 'hunting insect' \\
\hline 25 Tiklahawaa gojar T & Centipede sp. & & $\begin{array}{l}\text { Tika }=\text { red point Hindu people } \\
\text { wear on their foreheads }\end{array}$ & Rolling like 'tika' when touched \\
\hline 26 Tiree $\mathrm{T}$ & Locust & & Tiree $=$ arrow & Swarms like arrow \\
\hline 27 Tiric saap $\mathrm{T}$ & Snake sp. & Thriksha T & Tiric $=$ arrow & Stands, flies and is as long as an arrow \\
\hline 28 Udnahunwa ghun $\mathrm{T}$ & Pulse Beetle & & $\begin{aligned} \text { Udhne } & =\text { to fly } \\
\text { ghun } & =\text { weevil }\end{aligned}$ & $\begin{array}{l}\text { Pulse weevils are more active flyers } \\
\text { than other storage pests }\end{array}$ \\
\hline
\end{tabular}


Table 6. Continued.

\begin{tabular}{|c|c|c|c|c|}
\hline Tharu name (romanized) & English name & Other names & Gloss & Explanation \\
\hline \multicolumn{5}{|l|}{ Habitat/host } \\
\hline 1 Dhongree kiraa $\mathrm{T}$ & Wild Silk Moth, pupa & & Dhongree $=$ can, case, pipe & Pupa in a very strong cocoon \\
\hline 2 Ghoda maachee $\mathrm{T}$ & Horse fly & & Ghoda $=$ horse & \\
\hline 3 Guhak machee $\mathrm{T}$ & Blowfly & & Guhak $=$ stool, dung & \\
\hline 4 Kaathkholuwaa T & Longhorn Beetle, larva & Kaate kiraa $\mathrm{N}$ & $\begin{array}{l}\text { Kaath }=\text { wood } \\
\text { kolnu }=\text { boring, opening }\end{array}$ & Living in holes bored into the tree \\
\hline 5 Kattiulaa $\mathrm{T}$ & Wood borer & & Kaath $=$ wood & Living in wood \\
\hline 6 Kath kiruwaa $\mathrm{T}$ & Bed bug \& Wood borer & Udus N/T & $\begin{array}{l}\text { Kaath }=\text { wood } / \text { bed, } \\
\text { kiruwaa }=\text { insect }\end{array}$ & Found in bed \\
\hline 7 Kukur machee $\mathrm{T}$ & Dog fly & & Kukur = fly & Pest on dogs \\
\hline 8 Pat bicchee $\mathrm{T}$ & Saddleback Caterpillar & & $\begin{array}{l}\text { Pat }=\text { leaf, } \\
\text { bicchee }=\text { scorpion }\end{array}$ & Rests on leafs, poisonous hairs \\
\hline \multicolumn{5}{|c|}{ Derived from Sound Produced (echoic names) } \\
\hline 1 Bhamuraa $\mathrm{T}$ & Bumble/Carpenter Bee & Bhaaraa $\mathrm{N}$ & & Humming sound \\
\hline 2 Jhingauraa $\mathrm{T}$ & Dragonfly & & $\begin{array}{l}\text { Jhing-jhing-jhing (sound), } \\
\text { gaura = making }\end{array}$ & Chirping noise \\
\hline $\begin{array}{l}3 \text { Bhurburuwa- } \\
\text { sursuruwaa T }\end{array}$ & Sphinx moth & & Surh $=$ trunk & Insect with trunk \\
\hline 4 Ucrungiyaa $\mathrm{T}$ & Field Cricket & & $\begin{array}{l}\text { Ucrun (sound), } \\
\text { gaura = making }\end{array}$ & Chirping noise \\
\hline 5 Cingairaa $\mathrm{T}$ & Field Cricket/Cicada & & $\begin{array}{l}\text { Cing-cing-cing (sound), } \\
\text { gairaa = making }\end{array}$ & Chirping noise \\
\hline $\begin{array}{l}6 \text { Kanhyan, Kanaya, } \\
\text { Kaanhaa phatingaa }\end{array}$ & Field Cricket & & $\begin{array}{l}\text { Kaanhaa = Lord Krishna's name } \\
\text { when he plays the flute }\end{array}$ & $\begin{array}{l}\text { Singing, making music like } \\
\text { Lord Krishna }\end{array}$ \\
\hline \multicolumn{5}{|l|}{ Human Impact } \\
\hline 1 Aakh phoruwaa $\mathrm{T}$ & Praying Mantid & & Aakhaa $=$ eyes, phornu $=$ to tear & $\begin{array}{l}\text { Its feared due to alerted habit } \\
\text { of pulling out eyes }\end{array}$ \\
\hline \multirow[t]{2}{*}{2 Anggar kotuwaa $\mathrm{T}$} & $\begin{array}{l}\text { Water Tiger and } \\
\text { Trichoptera larva }\end{array}$ & & Anggar = finger, & Attacks fishing people \\
\hline & & & kotuwaa $=$ biter & \\
\hline 3 Cipniyaa $\mathrm{T}$ & Ant sp. & & Cipne $=$ pinching & The 'pinching one' \\
\hline 4 Gaandhee $\mathrm{T}$ & Bug & & Gandh $=$ bad smellstinks if touched & \\
\hline 5 Gurhaniyaa T & Dragonfly & Jhingauraa $\mathrm{T}$ & Gurhaniyaa $=$ doll for Gurahi-festival & \\
\hline 6 Kansutariyaa T & Wall Millipede & & Kan $=$ ear, sutriya $=$ sleeping & Causes thread-like wound in ears \\
\hline 7 Gandauree cimtaa $T$ & Ant sp. & & Gandhauree $=$ stinking & The 'stinking ant' \\
\hline
\end{tabular}

social paper wasp, in contrast, is referred to in plural but lacks the singular form.

Appearance and ecology not only shape nomenclature, it is also the nomenclature that influences people's perception. The praying mantis may serve as an example: Although harmless and beneficial, it is named after its alleged habit of pulling out people's eyes. Feared throughout the country, the myth persists despite lacking evidence. Misleading is also the name of the earwig or centipede (kansutteria $\mathrm{T}$; kaan = ear). The story of earwigs and centipedes entering ears, causing painful infections and penetrating the brain is prevalent all over Nepal. Parents enforce the belief by warning their children not to sleep in the grass when they are supposed to collect fodder for livestock, as dangerous earwigs could crawl into their ears. Such misleading names do injustice to insects that have a valuable function in the agro-ecosystem.

Indigenous taxonomies are rich when the variance of any phenomenon critical to the survival of the community concerned is high.

As most Nepalese are agriculturists, it might be fair to assume that they generated a wealth of knowledge on insects, in particular on pests. In Tharu folk classification, however, only a few kiraa are further differentiated on the specific level and most of them are not pests. Among them are Diptera (flies), Hymenoptera (wasps, bees, and ants), centipedes/millipedes, bugs, 
coleopteran storage pests, and snakes. Most of them are species that are preferably avoided. It is highly probable that plant pests were irrelevant in traditional agriculture, as they simply did not reach a critical level. Plant pests, i.e., herbivorous insects causing qualitative and quantitative loss in crops, are mainly a result of modern cropping practices, improved varieties, fertilizer, and pesticide use. As such, they constitute a recent phenomenon in Tharu agriculture. In general, Nepalese farmers have less knowledge of pest insects than farmers that have been subjected to Green Revolution technologies. In the study of Price (2001), for instance, Filipino farmers identified as many as twenty-six different insects found in the rice field. As traditional rice varieties expressed a higher pest resistance, Nepalese farmers were not forced to cope with pest insects and, thus, did not generate sophisticated knowledge of their control. This notion is further supported by the fact that traditional means of curative pest control are very limited. With the introduction of pest-susceptible high-yielding varieties, however, the situation changed dramatically. In future, farmers will require a good understanding of pest management and insect-plant relationship. New varieties, therefore, need to be offered in a package together with the know-how to cope with potential pests.

Apart from insect groups with high diversity on the specific level, some groups (e.g., beetles, bugs, butterflies, grasshoppers, and dragonflies) are diversified on the generic level only. Observations of moderate diversity in naming bugs (Hemiptera) and beetles (Coleoptera) on the specific level, and their grouping in a single category, were made in Mexico (Aboytes Ruiz and Castro Ramírez, personal communication) and Bhutan (Schoubroeck et al., 1999). In Bhutan, farmers did not even have a collective term for beetles and bugs. In Nepal, literature refers to kapte kiraa for beetles, a term that is hardly used at the village level. In the Tharu language, beetles are specifically named as gongoir (dung beetle), padaira (bombardia beetle) or dhelbokuwaa (longhorn beetle). In total, 19 different beetle names are used. This corresponds with findings regarding insect classification in an Amerindian community (Wyman and Bailey, 1964).

Hemipteran bugs are called gaandhee, derived from their smell (gaandh $=$ bad smell). In contrast to the scientific classification, gaandhee also refers to other species that emit a smell, such as the ladybird beetle. The hemipteran gaandhee contains only one species on the sub-generic level (lal gaandhee). Other hemipteran bugs have their own names without reference to gaandhee.

Folk classification of insects also differs from scientific classification for sound-producing species, such as crickets (cingairaa, ucrungiyaa), ciadas (cingairaa), and dragonflies (jhingauraa - fluttering wings), whose names are often confused and used interchangeably due to their similarity. All of them have the etymological root of "sound-making."

Some insects are not named at all. The absence of names, however, does not necessarily imply absence of a category (Berlin, 1992). This is certainly true for the Tharu, who recognize more insects than they actually name. They can talk about certain species without naming them. The description of morphological features and some contextual information can be sufficient. Interestingly, only a few Tharu farmers know how to name leaf- or plant hoppers although rice has been cultivated for centuries. They recognize them as annoying insects attracted to light and sometimes accidentally getting in their eyes. They do not recognize them, however, as a virus transmitter or pest. In fact, plant hoppers only became important when monoculture and pesticides were introduced for rice. Similarly, the ladybird beetle is widely known but seldom named. Recognized but not named are also the click beetle (Elateridae), stag beetle (Lucanidae), white fly (Aleyrodidae), green lacewing (Chrysopidae), and the back swimmer (Notonectidae).

Parasitoids or beneficial predators are neither recognized nor named. This is an almost universal observation in farming communities in developing countries (Bentley, 1993; Bentley et al., 1994; Bentley and Rodríguez, 2001). Accordingly, farmers lack the key concept of parasitism, as well as a basic paradigm for biological control. Other insects that are generally not recognized are the rice leaf folder (Cnaphalocrosis medinalis), mango fruit fly (Dacus dorsalis), walking stick (Phasmidae), mayfly (Ephemeroptera), silverfish (Thysanura), stone fly (Plecoptera), tiger beetle (Cicindelidae), blister beetle (Meloidae), glowworm (Phengodidae), scorpion fly (Mecoptera), and crane fly (Tipulidae). Within Nepal, these gaps in recognition are not cross-culturally consistent. Most of the unnamed species listed above are recognized and named in the hill regions of Nepal. This demonstrates that local knowledge on insects is strongly related to agricultural development, people's livelihood system, and the local environment.

Animals that are absent or rare in an area are usually unlikely to feature in classification (Ellen, 1993). In Tharu classification, the horse fly and the slug are commonly known despite their physical absence.

People's environmental perception is generally dominated by the visual sense (Ellen, 1996). As mentioned earlier in the chapter, Berlin (1992) found it likely that salient morphological and behavioral features are encoded directly in names to facilitate learning. For insects, however, the small size hampers recognition of specific morphological features. Con- 
Overall, agronomic criteria were most important followed by ecological, human-directed, physiological/behavioral, and morphological criteria. The high percentage of agronomic criteria indicates that Tharu farmers indeed relate insects to crop production, host plants, and damage, and that the farmers' common statement that all kiraa are bad does not conclusively imply the absence of a concept regarding pests and beneficials. The triad test shows that farmers are aware of those insects that cause harm to crops and those that do not. Thus, the former statement is based on the perception that kiraa are either harmful to crops, to humans, or to livestock. Kiraa that neither damage crops nor harm humans are less relevant and, thus, less present in the farmers' perception.

Human-directed criteria used by the Tharu were generally negative (stinging, biting, and irritating) with the sole exception of the honey-producing bee and white grubs, which are used as fish bait. The use of insects as food or for medicinal purpose was not mentioned.

Physiological/behavioral criteria focused almost exclusively on locomotion (flying or not flying) and ecological criteria on habitat and food sources. A similar observation was made by Morris (1979), who found that movement was the pervasive theme in the insect taxonomy of an Amerindian community.

Morphological criteria (color, size, appendices, and beauty) played a minor role for differentiation, although the exercise was conducted with a visual aid. This is surprising in two senses. First, from a methodological point of view and, second, in terms of the expected result.

Visual tools can have an impact on the respondent's choice (Borgatti, 1996b; Ellen, 1993) and lead to distorted results. If the respondents have only poor knowledge on the subject and less alternative structures on which to base similarity judgments, they may show a preference for morphological criteria (Boster and Johnson, 1989). Using a visual stimulus can also cause problems in cultures where photographs or pictures are not regularly viewed (Werner and Fenton, 1970). In this particular case, however, the use of picture cards did seemingly have no encouraging effect on the reference to morphological criteria.

Second, these findings are surprising, as morphological structures and plans are said to shape categorization and to be determinant for classification of flora and fauna (Berlin, 1992) and insects in particular (Posey, 1979: 81). Posey was a strong supporter of the idea that folk classifications are very similar to the scientific system. He found that the Kayapó recognize basic object-level categories encoded in gestalt fashion with gross morphological features being the prevailing criteria. This might be true for ethnobiolo- gical nomenclature and for the recognition of plants or larger animals, but not conclusively for insect taxonomy. Posey's folk-entomological findings must be interpreted in the light of his methodology. In his and other ethnoentomological studies (Wyman and Bailey, 1964), respondents were requested to group pinned insect specimens and to explain why they were similar or different. By doing so, he excluded most natural stimuli (smell, locomotion, or host/habitat) and encouraged the use of morphological criteria. This, of course, led to a folk classification very similar to the scientific classification that is also mainly based on morphology. It remains questionable whether Posey's findings really reflect the people's folk classification. A few years back, I supported Posey's statement. In a pre-test conducted with real insect specimen in Eastern Nepal, respondents did indeed group insects according to morphology. Based on the findings of the present study and historical data on entomology (Bodenheimer, 1928), however, it must be assumed that such grouping is an artifact based on the exclusion of natural stimuli. In nature, farmers obviously lack the opportunity to scrutinize insect morphology. Posey himself reported that "informant error in identification [...] out of the environmental context was found to be very high," thereby indicating that morphology alone was insufficient for insect recognition. The notion that morphological features are of minor importance for insect recognition is further supported by the findings from the triad sorting of rice field insects conducted by Price, where morphological criteria attributed to insects were few in number (personal communication). Price, however, worked with names (no visual stimulus). Thus, it can be concluded that perception, in contrast to naming, is strongly influenced by agronomic considerations, ecological knowledge, or human impact. These features, however, are less unique or distinct compared to morphological criteria.

Perceptional gender differences (triads). The frequency of selecting an insect from the triads and the type of explanation why it was chosen were different for male and female respondents. Men generally used more vague attributes like "harmful" or "harmless," while women were more specific, often referring to the host plant. The rat, for instance, was referred to by women as a hole-making storage pest, while men did not refer to the burrows at all. This clearly reflected that women normally repair and clean the damage. Women, the caretakers of the stored grain, showed a marked preference for selecting the grain weevil more often (62) than men (41). Women mainly described it as a wheat or storage pest but never as a rice pest. Men, in contrast, mentioned it eight times as a rice pest. Women distinctively described the stem borer as a rice pest (30) inside the stem (8). Men's criteria ranged 
from harmful (12), rice pest (13) living inside the stem (4), to aquatic (4). Almost half the criteria raised by women to differentiate bees referred to their sting (27). Honey-making (11) and hive-making (13) were less important. For men, stinging (12), honey-making (10) and hive-making (9) were of equal importance. Although the picture presented for "bug" showed a green citrus bug, most women defined it as a rice pest (33) or vegetable pest (14). For men it was, in the first instance, a harmful (15) rice pest (19). The answers reflected the increasing occurrence of rice bugs (Leptocoriza spp.) in the fields. The concept of predatory bugs was absent. The only distinct attribute for aphids as a vegetable pest was almost exclusively used by women (29). Women perceived earwigs as mainly biting (31). Men agreed that they bite (10) but, in contrast, also acknowledged that they are harmless to crops (8). The spider is a similar case. Women used only four different attributes: cobweb (36), harmless, inside house, and not flying. Men acknowledged that they are harmless (9) and make webs (26). Only one criterion referred to predatism. Both genders perceived the white grub as soil-dwelling (19/19). Women considered it as useful fish bait (7) whereas men refer to it as harmless (11). The praying mantis was characterized by few distinct features. As the insect is stigmatized by its misleading name aakhphoruwaa (lit. eye-tearing) as a dangerous insect attacking people and tearing out their eyes, many women and men referred to it as tearing eyes (11/6). However, more men (11) than women (5) acknowledged that it was harmless to crops. Solely women referred to the poisonous hair of the hairy caterpillar (15). As a mustard pest (11), it was of secondary importance. Men's criteria were manifold, yet they placed them as mustard pest (10) in first position.

These perceptional differences have their origin in the division of labor. Women are typically involved in tasks at household level including fetching water, cooking, kitchen gardening, and grain storage and childcare. Although they spend less time in the field, their knowledge of field insects is similar to that of the male farmers'. As the fields start in the backyard, women have plenty of opportunity for observation. Male tasks are more community- and fieldoriented. They do house construction, irrigation, livestock rearing, and field labor demanding great physical strength, such as plowing and threshing.

Similarity among insects was analyzed for the entire group of respondents and gender-separated sub-groups. Similarity levels were shown for each insect pair in the aggregate proximity matrix (high values referring to high similarity) and visualized in a two-dimensional dendrogram after submitting it to Johnson's hierarchical clustering (Figure 4). Due to the high variability within the criteria used by the male respondents and the consequent low similarity levels, only the data from female respondents with higher similarity levels $(0.7)$ were analyzed further.

In the women's dendrogram, the dragonfly and butterfly were clustered at the highest similarity level (0.7) as harmless, flying insects living above the ground. The grasshopper and the praying mantis form a second peak $(0.65)$ in the same cluster. They are also flying, yet as leaf-feeders not harmless. The aphid connects these two peaks by joining the grasshopper and mantis as a leaf-feeder. The high similarity to butterfly $(0.55)$ could be an artifact. A less distinct peak on the left (0.6) is formed by the stem borer and white grub, both hidden in the soil or inside the stem. They are not grouped together as pests as the white grub is perceived as useful fish bait. The rat joins the cluster of non-flying, ground/soil-dwelling species. The weevil's close position to the dragonfly is an artifact due to the two-dimensional scale. The proximity matrix reveals that the weevil is most similar to the grasshopper (0.5), as they are both considered as pests. The cluster on the far left contains flying insects (wasp, bee, bug), the cluster on the far right non-flying insects (earwig, spider, hairy caterpillar).

It is important to note that the concept of harmful and harmless insects did not appear in the dendrogram as two distinct peaks as found, for instance, in the triad sorting of rice field insects done by Filipino farmers. These farmers classified insects in pests and beneficials independent of whether they had undergone Integrated Pest Management (IPM) training or not (Price, 2001). In this study, however, the concept of beneficial and harmful insects could only be traced by analyzing the criteria in depth.

Insect classification (successive pilesorts). The farmers' conceptualization of kiraa is very different from the English Folk Zoology where animals, birds, fishes, snakes, and insects are taken as different "life forms," i.e., distinct polytypic categories few in number (Wierzbicka, 1996). Within the group of kiraa, the analysis of 20 pilesorts gave strong evidence that there is no separation between the class of insects, non-insect arthropods, and other animals belonging to the domain of kiraa. This can be partly explained by the fact that mostly non-morphological criteria were used for differentiation. Gender-based differences were detectable in regard to the agronomic criteria used. Male farmers used more criteria related to crop production (16) than female farmers (5). Although maximum knowledge scores were found among women, indicating that they were closer to the "culturally correct pilesort," the average knowledge scores were about the same for female (0.42) and male respondents $(0.43)$. 


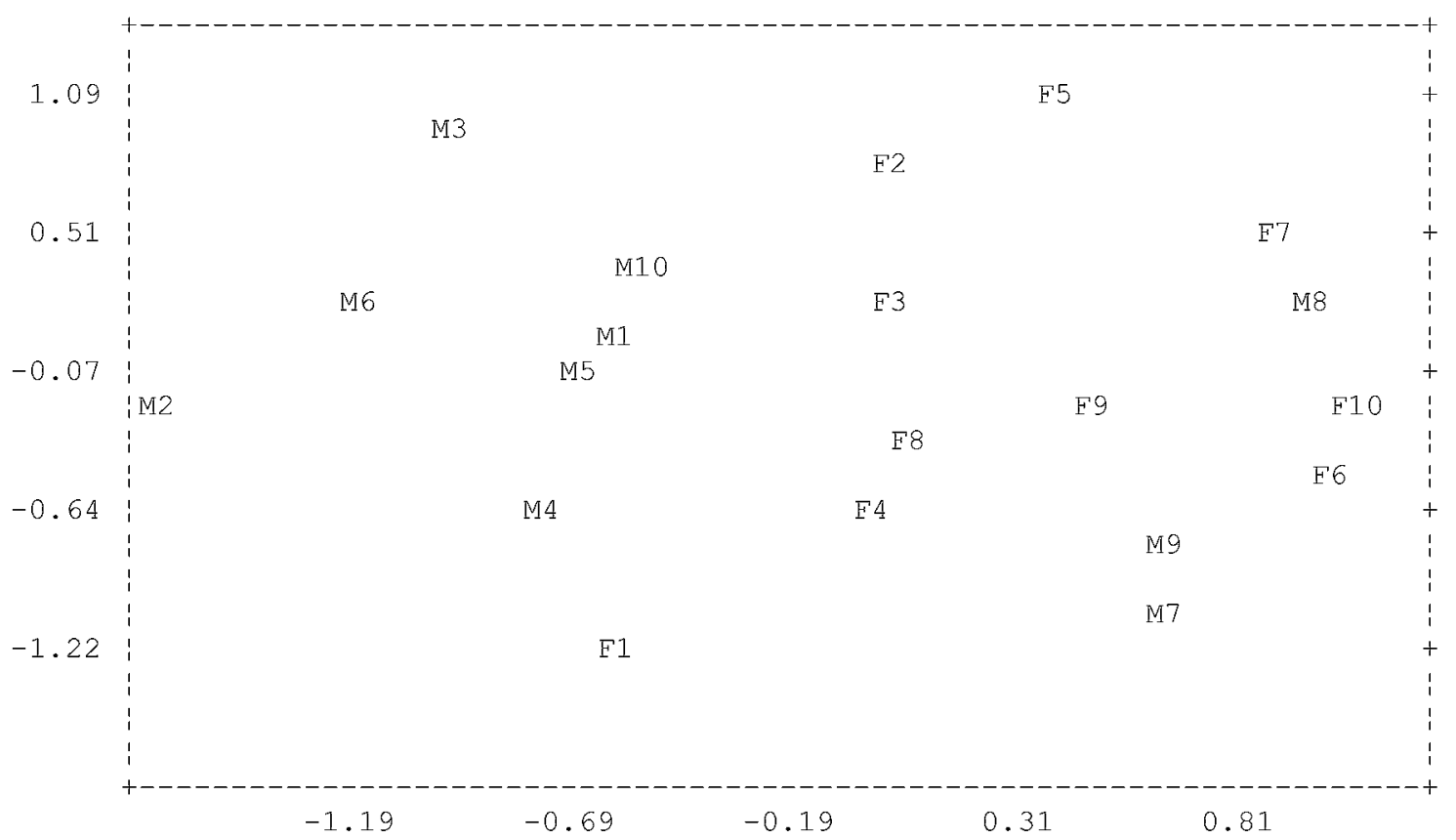

Figure 5. Visual representation of similarities between successive pilesorts conducted by male $(\mathrm{M})$ and female respondents $(\mathrm{F})$.

The minimal residual Eigenvalues obtained from factor analyzing the data for three factors indicated that sub-cultures exist, i.e., the assumption that there is one culture was wrong (ratio 2.3). Indeed, the multi-dimensional scaling (MDS) showed clusters of male (right) and female respondents (left) (Figure 5). MDS provides a visual representation of a complex set of relationships. The procedure performs non-metric multidimensional scaling. Given similarities between items (e.g., respondents or insects) are first recorded as an aggregate proximity matrix. Each cell records, for instance, the number of respondents who placed specific items into the same pile. The higher the value in a cell, the higher is the degree of similarity. From these data, the program computes (i) respondents' estimated level of knowledge, (ii) the model's best guess as to the right answer based on weighted average of respondents, and (iii) a chance-adjusted agreement matrix. The latter two can be used for MDS associating species or respondents with points in a two-dimensional space.

For further analysis, five outliers $(2,3,6,11$, 15) with the lowest cultural competence (low estimated knowledge levels) were excluded with the risk of getting a truncated view of the cultural reality. The remaining 15 respondents met the requirements for being one culture (ratio 3.1). The removal of low-competence respondents from the sample had, however, almost no impact on the result of the MDS.

The MDS of the best guess as to the culturally correct pilesort of 15 farmers showed no groupings of pests and beneficials (Figure 6). A clear distinc- tion is made between "harmful, dangerous, poisonous, stinging and biting kiraa" (upper half), and those "harmless" to humans (lower half). Harmful species are arranged according to the degree of danger, placing the greatly feared snake and scorpion to the left and the less aggressive and poisonous praying mantis and spider to the right. A second line separates ground and soil-dwelling kiraa (left) and those living in or over the plant canopy (right). Similarities between species were found between the frog, earthworm, and white grub (ground dwelling), dragonfly, butterfly, and praying mantis (flying), snake and scorpion (extremely poisonous), and ant, hairy caterpillar, and centipedes (less dangerous). This demonstrates that the grouping of kiraa in the successive pilesort exercises was based mainly on functional criteria. In particular, the frequency of mention and the "salience index," computed for each criterion given during the pilesort, showed highest values for human-directed criteria. The first split of the domain was mostly assigned to the biting/stinging character of the species (16; SI 62.3). The second split occurred according to the habitat (16; SI 55.0) and the third again according to human impact (15; SI 52.7) followed by locomotion (9; SI 34.5). Agronomic criteria (8; SI 26.8) were less relevant while morphological criteria (5; SI 12.7) were almost irrelevant. Accumulating the salience index of these criteria groups showed that human-directed criteria attributed to almost half of the splits (46\%), followed by ecological (25\%), physiological/behavioral (12\%), agricultural $(11 \%)$, and morphological criteria $(6 \%)$ $(n=220)$. For human-directed criteria, farmers dif- 


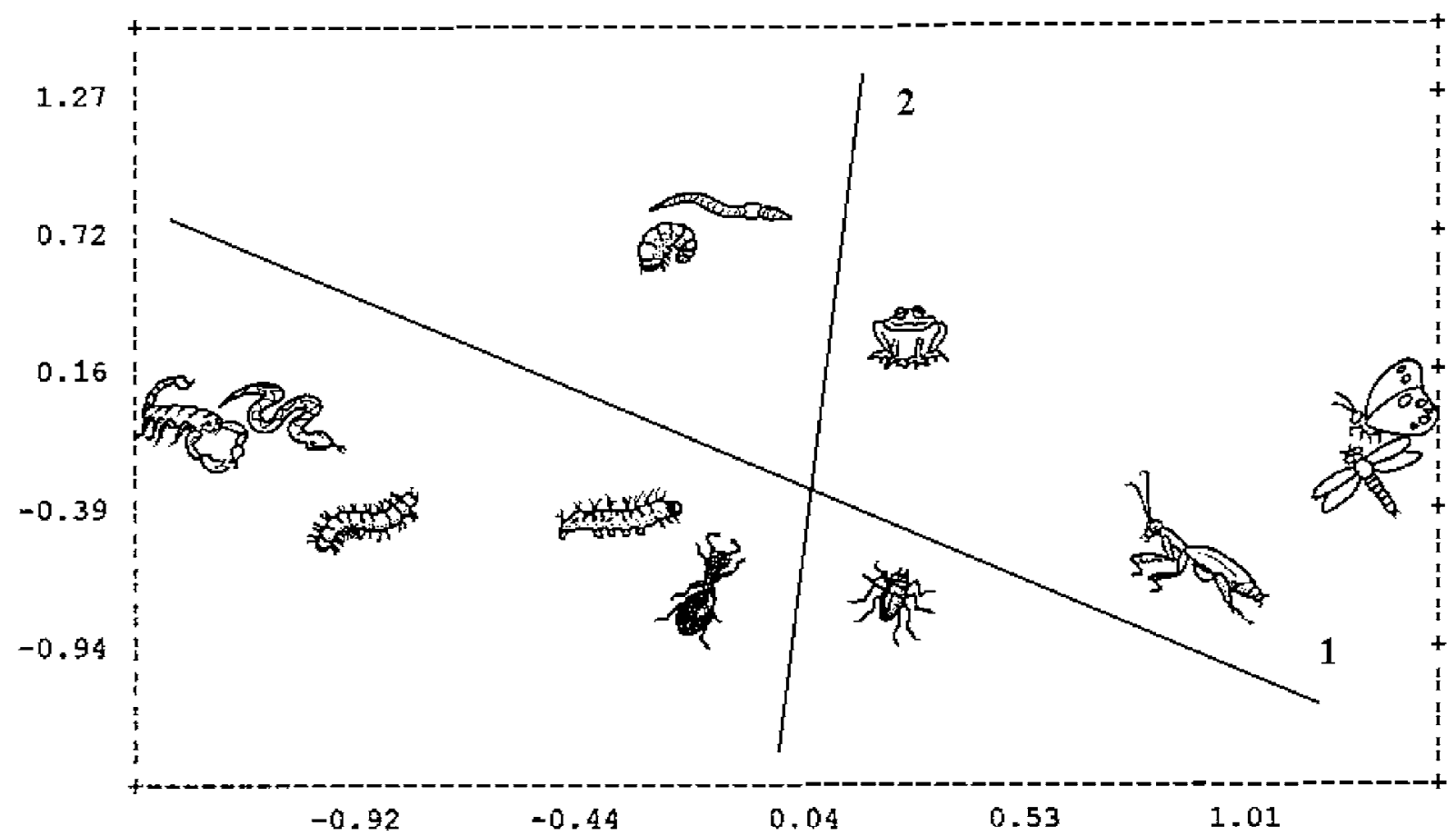

Figure 6. Multi-dimensional scaling of the best guess as to the culturally correct pilesort $(n=15)$.

ferentiated between stinging/biting accidentally or purposely; between moderate, severe, and lethal poisons, between immediate skin irritation, swelling, pain, duration, and delay of pain. Spiders are considered as harmful due to their irritating urine. The praying mantis is mistakenly assumed to attack children and tear out eyes. These findings stand in strong contrast to the findings of A. Ruiz and C. Ramírez (personal communication), who found that the criteria used by a Maya group of Mexico for pile sorting 62 cards with insect figures were based on morphological characteristics, color, sound, similarities to other animals, habitat, and feeding habits.

Consensus analysis. Few aspects of the qualitative data were further validated by means of consensus analysis. The assumption that there is one culture was found to be valid for the entire sample $(n=40)$ and for the gender sub-groups $(n=20)$ regarding all three topics: insect ecology (ratio 11.1), storage management (ratio 12.5), and the sacred (ratio 5.7). Differences based on age and gender were virtually absent.

In the field of insect ecology, lifecycle-related topics raised maximum uncertainty and disagreement. High numbers of farmers supported scientifically wrong statements or said that they do not know. Male farmers disagreed more often than female farmers, who admitted being ignorant in certain issues. Similar findings were made in the field of storage management, where the data provided evidence that the belief in the supernatural is present and alive in the community, independent of gender, age and formal education. Disagreement existed concerning the proper performance of a practice but not on the suitability of the practice perse.

Knowledge of population dynamics. Traditional agriculturists possess a wealth of environmental and ecological knowledge that goes beyond simple naming and classification (Brosius et al., 1986). Also, Tharu farmers know more about insects than just the names. However, this knowledge needs to be differentiated as follows: (i) scientifically valid knowledge, (ii) wrong assumptions and explanations with an internal logic, thus, with its own validity, and (iii) concepts carried on without sound base of observation or logic.

A large part of the farmers' concepts of insect ecology is drawn from experience or observation made in livestock rearing. From the observation of mating grasshoppers, farmers conclude that male and female insects live in pairs, just like husband and wife although the two of them cannot be differentiated. It is clear that insects are both viviparous and oviparous. Caterpillars are believed to mate and lay eggs, as they are sometimes seen together in one place. They are not considered as the larval stage of butterflies, as there is no clear concept of insect reproduction with complete metamorphosis. Small insects are generally considered the progeny of larger ones. As many pests appear in large numbers, farmers assume that insects lay a large number of eggs. Interestingly, farmers sense that large 
insects live longer than small insects estimating their life span from a few months up to several years. Drawn from their own experience, women farmers believe that over-crowding of insects is prevented by high mortality rates of eggs and babies (50\%). Further, insects are killed by pesticide or die naturally like plants. Predators are not mentioned as a mortality factor in the first instance. After probing, birds, lizards, and reptiles were referred to. Some predators, such as the potter wasp (kumhaniya T), are known but mistaken. Having observed them making mud nests and carrying home an insect species belonging to another group, the potter wasp is understood to practice child abduction. Instead of making their own progeny, they rob an insect and foster it until it becomes one of their own. The same idea of child adoption was common in ancient China (Bodenheimer, 1928). Few farmers observed Ladybird beetle preying on other species. Its bold appearance gave it the name bhaise gandhi $\mathrm{T}$ (lit. buffalo bug).

Living in a dynamic world, the Tharu are well aware of fluctuations in the insect populations conditioned by the changing seasons. During the hot and dry season, flies, mosquitoes, bedbugs and fleas become a common nuisance in their homesteads. During the rainy season, snakes, scorpions, and centipedes reach peak populations. In winter, most insects disappear and only a few remain in the fields. It is a common belief that insects, the rice bug in particular, migrate to the warm forest repelled by the food scarcity in the harvested fields and the chilly winter mist in the open ground. There, they hide under bark or burrow underground. Only with the rising spring temperature and pre-monsoon rains penetrating the ground, are they driven out from their resting-places and reappear in farmers' fields. God gave them the underground as a home where they belong and originate from. Hence, insect occurrence in the field is temporary and limited to the summer season.

This concept gives a nice example of wrong assumptions with an internal logic. This explanation is closely linked to the observation that mustard fields in winter appear deserted, in contrast to the enormous insect diversity encountered after the onset of the summer rain. In Tharu culture, the forest is conceived of as wild and the dwelling place of ghosts and evil spirits that, of course, provide good company for noxious insects. As forests look deserted in winter, farmers assume that the insects are hiding underground.

Male farmers, the main cultivators in the field, see a positive correlation between temperature, rainfall, and insect occurrence. They further observed that high nitrogen input (chemical fertilizer, manure) and drained soils enhance pest populations in rice fields. In winter, the army worm (sundee $\mathrm{T}$ ) appears in the mustard fields as soon as there is some overcast.
Farmers derive the possible reasons for which insects produce sound from their own experience. Thus, some insects cry due to starvation like hungry babies. Others, with God-given voices sing out for joy or to attract partners. Appealing physical features are also a gift of God. The idea of camouflage, defensive appendices, and patterns is not recognized.

Pest control. Knowledge of traditional pest control methods is scarce in terms of both preventive and curative methods. The lack of knowledge of curative methods can be explained by low pest pressure in the former agricultural system. Indeed, local rice varieties had no pest problems until recently except for occasional locust occurrence. Thus, farmers had to cope with various pest insects only after the introduction of high yielding varieties about one decade ago. Obviously, the time span was too short to generate extensive knowledge related to pest control.

Field pests are controlled by preventive methods, such as consequent weeding and sanitary measures that destroy potential habitats. As a curative method, cold ash is applied against insects and diluted buttermilk against fungal diseases. Unlike many Buddhist tribes in the Himalayas (Schoubroeck et al., 1999), farmers feel entitled to kill insects, although they are part of God's creation. There is, however, a clear rule determining which kiraa can be killed and which not. While the Sphinx moth (Sphingidae) is protected, other nocturnal moths and diurnal butterflies can be killed. Dung beetles, appearing as traitors in Tharu lore, can be killed. Fireflies, dragonflies, and potter wasps, however, belong to the protected species.

The use of chemical pesticide for field crops is uncommon. It is widely believed that chemical pesticides, being incompatible with traditional means of spiritual pest control, trigger more pests. Thus, up to the present day, farmers rely more on spiritual means of pest control than on chemical pesticides. A buffalo skull and a cracked pot, for instance, are commonly displayed in kitchen gardens to repel the evil eye. The rice bug worship and the dragonfly festival are the most important rituals related to pest control.

Rice bug worship (gandhi puja). The rice bug (Leptocoriza sp., gandhi $\mathrm{T}$ ) is the most feared pest in Gobardiha. To prevent the pest from invading the field, two bugs are caught, painted red and black and carried around in the community for final release outside the village. In addition, offerings in form of milk, wine, sweet roasted flour, fried bread, yogurt, and vegetables are made at the community level. Incense is burnt whilst they chant: "Go gandhi go! To others' fields!" asking the rice bug to leave their spiritual territory for others in adjacent areas. This worship is performed on a plastered floor at the center of the field and takes place in early December, immediately 
after rice harvest and in June/July during planting season.

The dragonfly festival. Dragonflies (gurhei or gurhania T) play the role of a scapegoat symbolizing the evil that threatens farmers' livelihood in form of vermin, disease, and wounds. To avoid such evils, the dragonfly is annually sacrificed in the course of a picturesque and colorful festival in August. One month before the main event, girls and their mothers make male and female dragonfly dolls out of old rugs and cloth. These colorful dragonfly dummies are fostered during the preceding weeks of the big sacrifice. Lined up in rows to sleep they are consoled with songs: "Don't cry my dragonfly doll, it's time to depart, time to go ..." On the festival day, the girls dress in their best clothes or mother's skirts, exchange the old dress of their dragonfly dummy with an new one and place it on a tray with rice pudding, puffed chickpeas, and flowers. Equipped with these offerings, the girls gather on the threshing ground outside the village in the late afternoon. Standing in a semi-circle, they wait for the boys to come. With the help of their grandfathers, these boys prepare a whip made of fresh thatch grass and decorated with flowers. Carrying the whip, they approach the threshing ground from different directions. Once the children are gathered, the village head commands the girls to throw their dolls into the center of the circle where the boys beat them to shreds. For their hard work, the girls reward the boys with roasted rice and chickpeas. At the end, the boys collect some dolls and throw them on the roofs of their homes, into the kitchen gardens, or fix them on their beds.

This festival has several implications. As carriers of evil, the dragonfly dolls are used for the annual purification of the village, as they are taken outside the village boundary where the evil is beaten away. Through this process, they are again cleaned and can be used to absorb more evil in the year to come. For that reason, they are taken home by the boys and put in places prone to evil. Placed in the kitchen garden, they prevent pest infestation. Placed on the thatched roofs that are commonly covered with gourds and pumpkins, as they repel red pumpkin beetles. This is enforced by throwing the whip and a small leftover from the distributed food mixed with grass onto the roof. Tucked between the thatch grass bundles of the roof, it further prevents snakes from dwelling there. Moreover, people keep one shred of a broken doll under their beds to prevent bedbugs from biting. In general, this ritual should protect children from wounds and, if conducted on the proper day, repel snakes from the village.

Perception and knowledge of storage pests. The folk-entomological knowledge of the Tharu is not only rich for insects in general, but also in storage where their insect classification is more sophisti- cated than in other regions of Nepal. Ghun is a collective term for coleopteran storage pests that are further differentiated into: raato ghun (larger grain borer, Bostrichidae), udhnahunwa ghun (pulse weevils, Bruchidae), and laamtonghi ghun/cuce ghun (grain weevils, Curculinonidae). Cuhaa/putli is used for grain moths in general and lejlee for the Indian meal moth larvae (Plodia interpunctella) known by its webbing. Dhurwail stands for moulds. The main pests, however, are rodents such as mus (Rattus rattus) and dukri (small rodent).

Most farmers believe that stored product pests emerge spontaneously from the grain. Pest growth is initiated and triggered by grain moths whose respiratory heat creates weevils. Most of them agree that storage pests infest the standing crop and are transported with the commodity into the granary. They also believe that they hide inside the container and that they roam around and enter the bin through cracks and crevices. Others believe, however, that pests avoid empty containers. When the grain is finished, the pest will leave and frequently return to check the food situation. After several disappointing flights, they will give up and visit the bin no longer. With this concept in mind, farmers try to leave the bins empty for a while before re-filling them with fresh grain. Apart from the initial infestation at the time of filling, farmers worry that pest insects enter the container during grain removal, when the outlet is opened. Farmers therefore avoid opening containers during the storage.

There is general consent that Rhyzopertha dominica and other Coleopteran storage pests on rice became serious pests a few years ago, coinciding with the wider cultivation of improved varieties and pesticide application in the storage. This notion has been confirmed by the Post-harvest Loss Reduction Division of the Department of Agriculture. Scientific data on this issue is not available so far, however, similar observations have been made in other countries (Compton et al., 1993; Fujisaka et al., 1992; Morales and Perfecto, 2000).

The high grain loss caused by rodents is often explained by farmers' daylong absence from home creating a favorable environment. This is often the case in laborers' and poor farmers' households. Farmers' physical presence is considered as the most effective means for rodent control. However, it is important to note that farmers feel capable of controlling rats as opposed to insect pests. Rodents' large size and habitat outside the bin allows farmers to act. In the case of hidden insect pests feeding inside the container or even inside the grain, farmers feel helpless. They are not aware of further options and solutions to improve the existing system. A few options, however, have been tested: About half of the households use fumigants 
and chemical amendments for storage pest control, as they are available, cheap, and believed to bear no health hazard for humans. As insecticides are called "medicine," "powder," and "tablet" in local language, they are assumed to kill insects only, without side effects to human and livestock. Moldy grain has an offtaste and is assumed poisonous as its consumption can cause headache and nausea. Yet, it is used for human consumption.

Insects as food. With a few exceptions, kiraa are not used as food in Tharu culture. Ghongee (Macrochlamys tugurium), an aquatic snail found in shallow irrigation channels and ponds, and crabs (gekta $\mathrm{T}$ ) are considered as delicacies. Frog legs and prawns (jhinge machaa $\mathrm{N}$ ) also enrich their diet. If in mood, the Tharu go rat hunting. Only large species are edible. Small mice and moles are rejected as they cause swelling and unease.

Knowledge of insect-transmitted diseases. In both rural and urban areas of Nepal, insects are important transmitters of diseases. Many are related to poor sanitation. In the Terai, mainly mosquitoes, flies, sand flies, fleas, and lice cause concern. Mosquitoes, for instance, are the vectors of malaria, filarial, and Japanese encephalitis (Igarashi, 1992; Thapa, 2000), while the sand fly is the vector of visceral leishmaniasis. Local people have a very poor concept of disease and disease-related organisms. They do not differentiate between disease, infection, parasites, or simple physical impact and are unaware of the importance of sanitation and hygiene. Although the list of kiraa-born disease compiled by local respondents appears quite long (Table 8), the individual's knowledge is limited to one or two examples.

Medicinal value of insects. With the establishment of modern health facilities and markets, the use of insects and their products in local medicine is disappearing. Though knowledge is still available, it is no longer applied.

To cure chest pain and mitigate breathing problems, for instance, honey mixed with egg was applied to the upper body and covered with Nepali paper. Bee larvae and meat of the common rat snake (shaman sarpa $\mathrm{N}$; Pietas mucous) were considered as a tonic for weak people. Cobra fat (Phettara sanpuwa $\mathrm{T}$ ) was used for massage to treat joint ailments, back and other aches, while scorpion pickled in oil rendered the oil effective against back pain, wounds, and bruises. Similarly, the spinal cord of a python hung around the neck or waist, depending on the site of pain, could cause relief. Eel blood applied to the hair enhanced natural hair growth and slugs, though not found in the region, were purchased at a price of two US Dollars, dried, fried, and given to patients suffering from body pain. Against headache, a water strider (garghumni $\mathrm{T}$ ) was wrapped
Table 8. Kiraa-born diseases listed by local respondents in Gobardiha $(n=30)$.

\begin{tabular}{|c|c|}
\hline Insect/kiraa & 'Disease' \\
\hline Mosquito & $\begin{array}{l}\text { Encephalitis, meningitis, malaria, } \\
\text { skin irritations, wounds }\end{array}$ \\
\hline Housefly & $\begin{array}{l}\text { Diarrhea, dysentery, nausea, } \\
\text { inserts/produces larva in wounds } \\
\text { of livestock }\end{array}$ \\
\hline Robberfly & $\begin{array}{l}\text { Skin irritations, wounds, fever, } \\
\text { weakens livestock rendering them } \\
\text { susceptible to other diseases }\end{array}$ \\
\hline Blowfly & Diarrhea, fever \\
\hline $\begin{array}{l}\text { Sand fly } \\
\text { (Phlebotomus } \\
\text { argentipes) }\end{array}$ & Visceral leishmaniasis \\
\hline Midge & Fever, headache \\
\hline Bed bug & Skin irritation \\
\hline Flea (rat) & Plague \\
\hline Hairy caterpillar & Skin irritation \\
\hline Grain moth larva & Diarrhea \\
\hline Centipedes & Bites cause fever and fainting \\
\hline Mice meat & $\begin{array}{l}\text { Enhances existing diseases of the } \\
\text { consumer, e.g., swelling }\end{array}$ \\
\hline $\begin{array}{l}\text { Round worm, } \\
\text { Hook worm }\end{array}$ & $\begin{array}{l}\text { Stomach problem, diarrhea, } \\
\text { weakness resulting in tuberculosis }\end{array}$ \\
\hline Bird Louse & Skin irritation (chicken) \\
\hline Wild silk moth pupa & $\begin{array}{l}\text { Digestive tract irritation (colic) in } \\
\text { livestock can result from accidental } \\
\text { ingestion }^{\mathrm{a}}\end{array}$ \\
\hline Nematoda sp. & Cutting cattle tails \\
\hline Liver fluke & $\begin{array}{l}\text { Intake with pond water, damaging } \\
\text { liver and lungs of livestock, } \\
\text { weakening }\end{array}$ \\
\hline $\begin{array}{l}\text { Aphid, Stem-borer, } \\
\text { Termite, Caterpillar }\end{array}$ & Causing plant 'disease' \\
\hline
\end{tabular}

${ }^{\mathrm{a} B o d e n h e i m e r ~(1928) ~ a n d ~ D a y ~(2000) ~ r e p o r t ~ a ~ s i m i l a r ~ p h e-~}$ nomenon caused by Bupestris or Meloidae Beetles swallowed by cattle.

in a piece of cloth and swallowed alive. The spongy egg case (ootheca) of the praying mantis was said to enhance healing when rubbed on the wound.

Insects as toys. It is mostly beneficial insects that are mutilated and used as toys. The legs of daddy longlegs (snape flies), for instance, are detached and used as small, jerking brooms. They remind people of the brooms used to sweep the grains to the traditional foot mill. Children enjoy the kicks and jerks of the torn-out grasshopper legs by squeezing the tights (femur) of the victim. Carpenter bees are welcome 
targets for catapults. If caught, they are pushed into a matchbox and used as a radio, as they make a humming sound. To make light bulbs, children collect fireflies and put them in a semi-transparent, hollow gourd. The habit of the longhorn beetles to cling stubbornly to pieces of bark, stones, or mud, makes them an appropriate toy for testing their strength. Dragonflies are changed into helicopters by replacing their abdomen with a straw. With their songs, children attract the Sphinx moth and encourage it to visit big pumpkin flowers they hold in their hands. Once the moth unrolls its proboscis to suck nectar from inside the flower, the children's hands will press the flower together catching the poor moth by its tongue to play with it.

Insect Stories. The short story of the dung beetle and cicada aims to induce moral values and to encourage children to become hardworking:

"The dung beetle (gongairaa T), active throughout the season, indefatigably rolled his dung balls for the cold season while the cicada rested idly on the tree, singing songs. One day, the cicada got hungry and asked the dung beetle for food. But he replied: 'You sing while I am working. For sure, I won't give you food'."

The dung beetle plays a very different role in the story of the dung beetle and the firefly (jogniya $\mathrm{T}$ ): "Both the dung beetle and the firefly are creatures made by Shankar, the creator of the earth. He sent these two insects down to earth to monitor the people's situation. The search of the blind dung beetle, clumsily roaming throughout the world, mostly ended up in a lethal accident by bumping into a house or colliding with someone. The soul of the dung beetle then returned to its creator and reported to him about the situation on earth: 'Lord,' it says, 'you should reduce the number of people down on earth. There are too many of them. Wherever I fly, I always bump into them or their houses'. The firefly's experience was different. Flying in the dark searching for people with its light, it never encountered them and finally died of exhaustion. Its soul returned to Shankar and reported: 'O Lord, you should increase the number of people down on earth. I spent my whole lifetime searching for them and never encountered even one'."

For this reason, the Tharu intentionally kill dung beetles while the fireflies are spared. The name for dung beetle, gongoiraa is derived from gongair, meaning "blind/slow/clumsy movement."

\section{Conclusions}

In the course of this study, it became clear that both knowledge and perception are extremely dynamic and vary according to the situation. Thus, we cannot con- clusively say that the farmers in Gobardiha perceive insects as a kind of $\mathrm{x}$ or classify them as a, b, or c, nor that these farmers have that much knowledge. However, as each method applied in this study approached the issue of knowledge and perception from a different angle, the whole set of methods brought forth fractions of the knowledge system found in the community, i.e., a small part of the reality. To fit these bits and pieces to a complete whole, further research with new approaches would be necessary. However, the insights we gained in the present study are valid findings and allow us to draw some conclusions.

To situate folk classifications of insects, the scientific classification system of Carl Linnaeus is taken as reference. The Linnean system is characterized by (i) its binary nomenclature allowing clear identification and classification of each species, and (ii) by its foundation on phylogenetic criteria such as insect metamorphosis and morphology (both non-utilitarian). Compared to the Linnean insect classification system, folk classifications are often found incomplete with fewer species included. Although some of them follow the overall structure and are based on similar concepts, traditional systems typically include utilitarian criteria for differentiation at higher levels.

Taking the Linnean system as a point of reference might do injustice to the qualities of folkclassifications, as it unconsciously includes the assumption that modern systems are more advanced and meaningful because they allow scientists from different parts of the globe to exchange information based on exactly the same principles and rules. It remains to be questioned, however, whether such a system is natural and the most appropriate for all. This study further established that pest management not only deals with pests and their host plants but primarily with farmers. For that reason, potentials and drawbacks of their knowledge, attitude, perception, and folk classification of insects need to be taken into consideration in agricultural extension programs that deal with pest management. In this vein, the present study provides several lessons:

a. Agricultural extension programs can build on existing concepts. The concept of insects being divine creatures and part of the agro-ecosystem that is kept in balance by nature and human effort, for instance, matches with the idea of IPM.

b. False concepts and wrong attitudes need adjustment to prevent misuse of pesticides. The common idea among the farmers that all insects are harmful conflicts with the idea of IPM. Such generalizations might lead to excessive use of pesticides once they are available. Moreover, false concepts regarding certain insect species (e.g., praying mantis, earwigs) might encourage using pesticides. The promotion of pesti- 
cides and the erosion of religious values and rituals further accelerate this trend.

c. Using and understanding farmers' vocabulary and language for effective communication. The term kiraa is polysemous, i.e., has different meanings. It sounds neutral to the extension worker who translates it with "insects." In contrast, for the farmer it is charged with negative feelings; kiraa are considered to be a mistake in God's creation and a more accurate translation of the term would probably be "vermin." The negative connotation it carries, implying that insects are less important and hence unworthy of attention, may hamper the success of participatory pest control or research programs.

d. Tharu folk classification of insects differs from the scientific classification system. Morphological criteria that are the basis for scientific classification of insects are almost irrelevant for the Tharu folk taxonomy while human-directed criteria are most important. While talking to farmers about insects it makes more sense to refer to terms of locomotion or habitat rather than physical appearance. Likewise, working with live specimens should be given priority over dead insect collections and pictures, where natural stimuli are absent.

The Tharu folk classification of insects is incomplete in the sense that it covers less species than the scientific system. Emphasis is laid on anthropogenic species. Insects without direct or obvious human impact are either missed or excluded from the classificatory system as a result of pre-classification. To manage an almost infinite mass of information, irrelevant species are sorted out.

Although the rough structure of the folk classification closely matches the scientific system, the former tends to intersect between scientific orders and families (e.g., 'stinking kiraa' covering hemipteran and coleopteran species). It is important to note, however, that there is no consensus among Tharu farmers on how to classify kiraa, as both functional and non-functional criteria are used for grouping them.

e. Tharu farmers lack a clear concept of pests and beneficials. Farmers do not have a proper concept of biological pest control. Although, a few predatory insects are recognized, their role in maintaining the natural balance in the agro-ecosystem is not understood. In addition, the concept of parasitoids is completely unknown. Farmers' criteria used for triad sorting, however, demonstrated that they relate insects to crops and livestock. It is well known which species cause loss or damage to crops and livestock, although the concept of pests and beneficials is not obvious at first sight.

The fact that insects are not grouped into pests and beneficials leaves scope to classify them spe- cifically according to their habitat, behavior, and abundance and, thus, provides a valuable base for IPM.

f. Perception depends on gender. Labor division has a detectable impact on the perception of male and female farmers as reflected in the results of triad analysis. Before launching pest management programs, it is therefore crucial to identify stakeholders and to adjust activities and information to their specific needs, interests, and competencies.

g. Functional criteria are more important for high salience of insects than morphological (nonfunctional) criteria. The fact that anthropogenic, abundant, and easily observable insects are prevalent in farmers' minds has consequences for effective communication in farmer education. To design training material, emphasis should be put on locomotion, sound, habitat, and behavior rather than on body structure.

h. Insect nomenclature is strongly shaped by morphology. The analysis of insect names has shown that insects' physical appearance is most important for naming, followed by behavior/locomotion, habitat/ host, human impact and sound. This finding should be taken into account when creating new Nepali insect names for those species without name. In a similar vein, biased insect names derived from wrong assumptions and misleading beliefs (e.g., mantis) should be replaced by neutral or functional terms.

Knowledge gaps in insect ecology. Lifecyclerelated knowledge and knowledge of diseasetransmitting insects is extremely poor. Thus, agricultural extension and farmer education is highly relevant in the field of insect ecology and lifecycles. Imparting the idea of insect metamorphosis and population dynamics provides farmers with a crucial base for decision-making in pest control.

Although most of the recommendations listed above relate to farmers' perception and knowledge, it is not the farmers who need to change their approach but rather the extension workers and scientists working in agricultural development. A change in approach is essential to improve extension and research on pest management. This requires, in the first instance, a change in extensionists' and scientists' attitudes, such as a familiarization with the perception and knowledge of farmers from the field. A necessary precondition for this is to get rid of the existing common attitude that scientific knowledge is superior to farmers' knowledge. Instead, an open attitude towards the potential value of farmers' ideas and experiences should be developed. This is especially needed in Nepal, where knowledge and technologies are still generated in research institutions and then transferred to farmers who are perceived as mere recipients. 
One important step towards facilitating such a change in attitude is the documentation and validation of farmers' knowledge and experiences. Documenting farmers' knowledge not only makes it accessible to extensionists and scientists but also adds value and strengthens farmers' self-esteem; that is important for local capacity building and for forging a partnership between them and the scientists/extensionists.

The Participatory Action Research framework provides one useful approach towards achieving farmers' capacity building. Taking their knowledge base and practices and combining them with scientists'/extensionists' expertise can contribute to the improvement of local practices in pest management. In future, the focus of scientists needs to shift from mere technology development to the facilitation of on-farm experiments conducted by the farmers themselves, eventually resulting in local capacity building.

\section{Notes}

1. Kiraa included in the triad test: rat, dragonfly, weevil, stem borer, wasp, bee, bug, butterfly, aphid, grasshopper, earwig, spider, white grub, mantis, hairy caterpillar.

2. There are three different methods to conduct Johnson's hierarchical clustering: maximum, minimum (single-link), and average distance. The average method assumes that the data are interval scaled. This is not the case for triad data. In the single-link method, the distance is defined by the largest similarity and is, therefore, the strictest of the three methods.

3. Kiraa included in the successive pilesort: scorpion, frog, snake, centipede, white grub, earthworm, spider, dragonfly, butterfly, ant, mantis, caterpillar.

4. The wooden plows used in Gobardiha are still constructed of thirteen parts.

5. Today, the ritual is practiced by worshipping the bullock pairs and the plow-man prior to the first plowing of the season.

6. Madhuca longifolia (Koenig) Macbride (English: Illipe Butter).

7. Narrated by Bhukhalu Chaudhary, shaman of Gobardiha. A similar story was documented by McDonaugh (1984a, b) where Mahadeo is the founder of the earth and father and consort of Gauri.

8. The blind snake is commonly feared due to its poisonous bite, although nobody has ever witnessed such an incident.

9. Apart from the data collected from other Nepalese communities in the course of the present research, there is little comparative data on quantitative knowledge available. Within Nepal, however, the quantitative knowledge of the Tharu is extraordinarily high (personal observation). From the Mexican Mayas of Quintana Roo, it was reported that they recognized 87 different insect names in the adult stage and some larvae (Aboytes Ruiz and Castro Ramírez, personal communication). Ellen (1969) recorded 131 different insect terms for the Nuaulu of South Central Seram.
10. Rai farmers of Tamku, Sankhuwasabha named 8 kinds of bees, 14 wasps, and 6 bumblebees.

11. A similar observation was made by Posey (1979) studying the Kayapó folk-entomological knowledge.

\section{References}

Agricultural Project Support Center (APROSC) (1986). Study on Village Level Food Grain Processing Methods in Nepal. Kathmandu, Nepal: Rural Save Grain Project.

Agricultural Project Support Center (APROSC) (1991). Glossary of Some Important Plants and Animal Names in Nepal. Kathmandu, Nepal: Agricultural Project Support Center.

Ajibola Taylor, T. (1974). "Motivation and method in ensuring protection of tropical produce from grower to his market." In The Proceedings of the First International Working Conference on Stored Product Entomology (pp. 11-17). Savannah, Georgia.

Altieri, M. A. (1990). "The ecology and management of insect pests in traditional agroecosystems.” In D. A. Posey and W. L. Overall (eds.), The Proceedings of the First International Congress of Ethnobiology - Ethnobiology: Implications and Applications, 1988 (pp. 131-143). Belém: Museu Paraense, Emílio Goeldi.

Anon. (1998). Statistical Pocket Book. Kathmandu, Nepal: HMG NPC Secretariat Central Bureau of Statistics.

Balée, W. (2000). "Antiquity of traditional ethnoentomological knowledge in Amazonia." Ethnohistory 47: 399-422.

Batchelder, W. H. and A. K. Romney (1988). "Test theory without an answer key?" Psychometrika 53: 71-92.

Beets, W. C. (1990). Raising and Sustaining Productivity of Smallholder Farming Systems in the Tropics: A Handbook of Sustainable Agricultural Development. Alkmaar, The Netherlands: AgBé.

Bentley, J. W. (1992). "Learning about biological pest control." ILEIA Newsletter 8: 16-17.

Bentley, J. W. (1993). "What farmers don't know." Ceres 26: $42-45$.

Bentley, J. W. and G. Rodríguez (2001). "Honduran folkentomology." Current Anthropology 42: 285-301 (online version).

Bentley, J. W., G. Rodríguez, and A. Gonzalez (1994). "Science and people: Honduran campesinos and natural pest control inventions." Agriculture and Human Values 11: 178-182.

Berlin, B. (1992). Ethnobiological Classification: Principles of Categorization of Plants and Animals in Traditional Societies. Princeton, New Jersey: Princeton University Press.

Bernard, R. H. (1994). Research Methods in Anthropology: Qualitative and Quantitative Approaches. New Delhi: Sage Publications.

Bodenheimer, F. S. (1928). Materialien zur Geschichte der Entomologie bis Linné, Vol. 1. Berlin: W. Junk.

Borgatti, S. P. (1990). ANTHROPAC 3.2. Columbia: Analytic Technologies.

Borgatti, S. P. (1996a). ANTHROPAC 4.0 (software). Natick, Massachusetts: Analytic Technologies. 
Borgatti, S. P. (1996b). ANTHROPAC 4.0 Reference Manual. Natick, Massachusetts: Analytic Technologies.

Boster, J. S. (1994). "The successive pilesort." Cultural Anthropology Methods 6: 11-12.

Boster, J. S. and J. C. Johnson (1989). "Form or function: A comparison of expert and novice judgments of similarity among fish." American Anthropologist 91: 866-889.

Brosius, P., G. W. Lovelace, and G. G. Marten (1986). "Ethnoecology: An approach to understanding traditional agricultural knowledge." In G. G. Marten (ed.), Traditional Agriculture in Southeast Asia (pp. 187-198) Boulder, Colorado: Westview Press.

Brown, C. H. (1979). "Folk zoological life-forms: Their universality and growth." American Anthropologist 81: 791-812.

Brown, C. H. (1990). "Ethnozoological nomenclature and animal salience.” In D. A. Posey and W. L. Overall (eds.), The Proceedings of the First International Congress of Ethnobiology - Ethnobiology: Implications and applications, 1988 (pp. 81-87). Belém: Museu Paraense, Emílio Goeldi.

Brown, B. J. and G. G. Marten (1986). "The ecology of traditional pest management in Southeast Asia.” In G. G. Marten (ed.), Traditional Agriculture in Southeast Asia (pp. 241272). Boulder, Colorado: Westview Press.

Bulmer, R. N. H. (1969). Field-methods in Ethno-zoology with Special Reference to the New Guinea Highlands. Port Moresby: University of Papua and New Guinea.

Caulkins, D. and S. B. Hyatt (1999). "Using consensus analysis to measure cultural diversity in organizations and social movements." Field Methods 11: 5-26.

Chambers, R. (1997). Whose Reality Counts? - Putting the First Last. London: Intermediate Technology.

Chitrakar, P. L. (1990). Planning Agriculture and Farmers: Strategy for Nepal. Kathmandu, Nepal: G. D. Chitrakar.

Compton, J. A. F., P. S.Tyler, P. S. Hindmarsh, P. Golob, R. A. Boxall, and C. P. Haines (1993). "Reducing losses in small farm grain storage in the tropics." Tropical Science 33: 283318.

Day, J. F., J. D. Edman, S. E. Kunz, and S. K. Wikel (2000). "Direct injury: Phobias, psychoses, annoyance, allergies, toxins, venoms and myiasis." In B. F. Eldridge and J. D. Edman (eds.), Medical Entomology (pp. 99-163). Dordrecht, The Netherlands: Kluwer Academic Publishers.

Diamond, J. M. (1966). "Zoological classification system of primitive people." Science 151: 1102-1104.

Dobremez, J. F., D. P. Joshi, and T. B. Shrestha (1985). Carte écologique du Népal: Région Nepalganj-Dailekh 1/25000, Cahier népalais Documents 12. Centre National de la Recherche Scientifique.

Ellen, R. (1979). "Introductory essay." In R. F. Ellen and D. Reason (eds.), Classifications in their Social Context (pp. 132). London: Academic Press.

Ellen, R. (1993). The Cultural Relations of Classification: An Analysis of Nuaulu Animal Categories from Central Seram. Cambridge, UK: Cambridge University Press.

Ellen, R. (1996). "Introduction.” In R. Ellen and F. Katsuyoshi (eds.), Redefining Nature: Ecology, Culture and Domestication (pp. 1-36). Oxford: Berg.

Fujisaka, S., P. Elliot, E. Jayson, and A. Dapusala (1992). "Where there has been no 'Green Revolution': Farmers' upland rices and related knowledge in Mindanao, Philip- pines." In The Proceedings of the International Symposium on Indigenous Knowledge and Sustainable Development, September 20-26, 1992 (pp. 96-110). Silang, Cavite Philippine: International Institute of Rural Reconstruction.

Garro, L. C. (2000). "Remembering what one knows and the construction of the past: A comparison of cultural consensus theory and cultural schema theory." Ethos 28: 275-319.

Gill, G. J. (1993). "Indigenous systems in agriculture and natural resource management: An overview." In D. Tamang, G. J. Gill, and G. B. Thapa (eds.), Indigenous Management of Natural Resources in Nepal (pp. 24-51). Kathmandu, Nepal: HMG Ministry of Agriculture/Winrock International.

Gupta, A. K., K. K. Patel, P. G. Vijaya Sherry Chand, A. R. Pastakia, J. Suthar, S. Shukla, D. Koradiya, V. Chauhan, A. Raval, C. Srinavas, and R. Sinha (1996). "Participatory research: Will the koel hatch the crow's eggs?" In CGIAR (ed.), New Frontiers in Participatory Research and Gender Analysis for Technology Development (pp. 209-243). Cali, Colombia: Centro International de Agricultura Tropical.

Gurung, G. M. (1994). Indigenous People: Mobilization and Change. Kathmandu, Nepal: S. Gurung.

Haverkort, B. and W. Hiemstra (1999). Food for Thought: Ancient Visions and New Experiments of Rural People. London: ETC/COMPAS/Zed Books.

Horton, D. E. and P. T. Ewell (1991). "Sweet potato pest management: A social science perspective." In R. K. Jansson and V. R. Kandakuri (eds.), Sweet Potato Pest Management - A Global Perspective (pp. 407-427). Boulder, Colorado: Westview Press.

Hunn, E. (1982). "The utilitarian factor in folk biological classification." American Anthropologist 84: 830-847.

Igarashi, A. (1992). "Epidemiology and control of Japanese encephalitis." World Health Statistics Quarterly 45: 299-305.

Jodha, N. S. (1998). "Reviving the social system-ecosystem links in the Himalayas." In F. Berkes and C. Folke (eds.), Linking Social and Ecological Systems: Management Practices and Social Mechanisms for Building Resilience (pp. 285-310). Cambridge, UK: Cambridge University Press.

Johnson, M. (1992). Lore: Capturing Traditional Environmental Knowledge. Ottawa: Dene Cultural Institute and The International Development Research Centre.

Krauskopff, G. (1999). "Covrées (Begaari) in Dang: Ethnohistorical notes." In H. K. Kuløy (ed.), Nepal: Tharu and Terai Neighbours (pp. 47-62). Kathmandu, Nepal: Educational Enterprises Mandala Book Point.

Krauskopff, G. (2000). "From jungle to farms: A look at Tharu history," In G. Krauskopff and P. Deuel Meyer (eds.), The Kings of Nepal and the Tharu of the Terai (pp. 25-48). Los Angeles, California: Rusca Press.

McDonaugh, C. (1984a). "The Tharu." In M. Brauen (ed.), Nepal leben und überleben (pp. 99-126). Zurich: Völkerkundemuseum der Universiät Zürich.

McDonaugh, C. (1984b). The Tharu of Dang: A Study of the Social Organisation, Myth and Ritual in West Nepal. Oxford: University of Oxford.

McDonaugh, C. (1999). "Aspects of social and cultural change in a Tharu village community in Dang, West Nepal, 1980 93." In H. K. Kuløy (ed.), Nepal: Tharu and their Terai Neighbours (pp. 223-233). Kathmandu, Nepal: Educational Enterprises Mandala Book Point. 
Morales, H. and I. Perfecto (2000). "Traditional knowledge and pest management in the Guatemalan highlands." Agriculture and Human Values 17: 49-63.

Morris, B. (1979). "Symbolism and ideology: Thoughts around Navaho taxonomy and symbolism." In R. F. Ellen and D. Reason (eds.), Classifications in their Social Context (pp. 117-138). London: Academic Press.

Motte-Florac, E. and J. Ramos-Elorduy (2002). "Is traditional knowledge of insects important?" In J. R. Stepp, F. S. Wyndham, and R. Zarger (eds.), The Proceedings of the Seventh International Congress of Ethnobiology - Ethnobiology and Biocultural Diversity, October 23-27, 2001 (pp. 207-224). Athens, Georgia: University of Georgia Press.

Nazarea-Sandoval, V. D. (1995a). Local Knowledge and Agricultural Decision Making in the Philippines: Class, Gender, and Resistance. Ithaca, New York: Cornell University Press.

Nazarea-Sandoval, V. D. (1995b). "Indigenous decision-making in agriculture: A reflection of gender and socioeconomic status in the Philippines." In D. M. Warren, L. J. Slikkerveer, and D. Brokensha (eds.), The Cultural Dimension of Development - Indigenous Knowledge Systems (pp. 155-173). London: Intermediate Technology.

Nazarea-Sandoval, V. D. and R. E. Rhoades (1994). "Rice, reason, and resistance: A comparative study of farmers' vs. scientists' perception and strategies." In R. S. Zeigler, S. A. Leong, and P. S. Ten (eds.), Rice Blast Disease (pp. 559-575). Wallingford, UK: CAB International.

Neupane, F. P. (1989). Crop Pests and Their Control (in Nepali). Kathmandu, Nepal: Prakashan Sajha.

Ooi, P. A. C. (2001). "From passive observer to pest management expert: Science education and farmers." In I. Guijt, J. A. Berdegué, M. Loevinson and F. Hall (eds.), Proceedings of a Workshop on Deepening the Basis of Rural Resource Management (pp. 167-178). ISNAR, RIMISP, IIED, CIRADTERA, INTA, ECOFORCA.

Panjiar, T. N. (2000). "In my own words.” In G. Krauskopff and P. Deuel Meyer (eds.), The Kings of Nepal and the Tharu of the Terai (pp. 49-55). Los Angeles, California: Rusca Press.

Posey, D. A. (1979). Ethnoentomology of the Gorotire Kayapó of Central Brazil. PhD, University of Georgia, Athens.

Posey, D. (1981). "Wasps, warriors and fearless men: Ethnoentomology of the Kayapó Indians of Central Brazil." Journal of Ethnobiology 1: 165-174.

Price, L. M. L. (2001). "Demystifying farmers' entomological and pest management knowledge: A methodology for assessing the impacts on knowledge from IPM-FFS and NES interventions." Agriculture and Human Values 18: 153-176.

Ramos-Elorduy, J. (1984). "Edible insects in Mexico and their protein content." Journal of Ethnobiology 4: 61-72.

Ramos-Elorduy, J. (1987). “Are insects edible? Man's attitude towards the eating of insects." In Food Deficiency Studies and Perspectives (pp. 78-93). UNESCO.

Ramos-Elorduy, J. (1997). "Importance of edible insects in the nutrition and economy of people of the rural areas of Mexico." Journal of Food and Nutrition 36: 347-366.

Ramos-Elorduy, J., E. Motte-Florac, M. Pino, and C. Andary (2000). "Les insects utilisés en médicine traditionelle au Mexique: Perspectives.” In A. Guerci (ed.), Ethnopharmaco$\operatorname{logy}$ (pp. 271-290). Genova: Erga.
Reichelfelder, K. H. and D. G. Bottrell (1985). "Evaluating the economic and sociological implications of agricultural pests and their control." Crop Protection 4: 281-297.

Romney, A. K. (1994). "When does consensus indicate cultural knowledge?" Cognitive Science News 7: 3-7.

Rusten, E. P. and M. A. Gold (1995). "Indigenous knowledge systems and agroforestry projects in the Central Hills of Nepal." In D. M. Warren, L. J. Slikkerveer, and D. Brokensha (eds.), The Cultural Dimension of Development - Indigenous Knowledge Systems (pp. 88-111). London: Intermediate Technology.

Schoubroeck, F. H. J. (1999). Learning to Fight a Fly: Developing Citrus IPM in Bhutan. The Hague, The Netherlands: CIP-DATA Koniklijke Bibliotheek.

Schoubroeck, F. H. J., W. Cheki, and B. B. Acharya (1999). "Gender aspects of IPM for citrus in eastern Bhutan." In E. van de Fliert and J. Proost (eds.), Women and IPM: Crop Protection Practices and Strategies (pp. 89-99). Amsterdam: Royal Tropical Institute.

Settle, W. H., H. Ariawan, E. T. Astuti, W. Cahyana, A. L. Hakim, D. Hindayana, A. S. Lestari, Pajarningsih, and Sartanto (1996). "Managing tropical rice pests through conservation of generalist natural enemies and alternative prey." Ecology 11: 1975-1988.

Sherwood, S. G. (1997). "Little things mean a lot: Working with Central American farmers to address the mystery of plant disease." Agriculture and Human Values 14: 181-189.

Smith, J. J. (1993). "Using ANTHROPAC 3.5 and a spreadsheet to compute a free-list salience index." Cultural Anthropology Methods 5(3), 1-3.

Soedjatmoko (1971). "Traditional values and the development process." Development Digest 9: 45-54.

Srivastava, S. K. (1999). "Culture dynamics among the Rana Tharus: The past in the present." In H. K. Kuløy (ed.), Nepal: Tharu and Terai Neighbours (pp. 9-25). Kathmandu, Nepal: Educational Enterprises Mandala Book Point.

Starna, W., G. R. Hemall, and W. L. Butts (1984). "Northern Iroquoian horticulture and insect infestation: A cause for village removal." Ethnohistory 31: 197-207.

Steiner, K. and U. Scheidegger (1994). "Improving soil fertility management in tropical highlands: Supporting farmers' initiatives." In A. E. Budelman (ed.), The Proceedings of the International Symposium on System-Oriented Research in Agriculture and Rural Development: Agricultural R\&D at the Crossroads, November 21-25, 1994 (pp. 93-103). Amsterdam, Holland: Royal Tropical Institute.

Tamang, D. (1993). "Challenges and opportunities in farm and community resource management in Nepal." In D. Tamang, G. J. Gill, and G. B. Thapa (eds.), Indigenous Management of Natural Resources in Nepal (pp. 13-23). Kathmandu, Nepal: HMG Ministry of Agriculture/Winrock International.

Thapa, V. K. (1997). An Inventory of Nepal's Insects (ProturaOdonata). Kathmandu, Nepal: IUCN Nepal Biodiversity Publication Series.

Thapa, V. K. (1998). An Inventory of Nepal's Insects (Lepidoptera). Kathmandu, Nepal: IUCN Nepal Biodiversity Publication Series.

Thapa, V. K. (2000) An Inventory of Nepal's Insects (Hemiptera, Hymenoptera, Coleoptera and Diptera). Kathmandu, Nepal: IUCN Nepal Biodiversity Publication Series. 
Thurston, H. D. (1992). Sustainable Practices for Plant Disease Management in Traditional Farming Systems. Boulder, Colorado: Westview Press.

Turner, R. L. (1997). A Comparative and Etymological Dictionary of the Nepali Language. New Delhi: Allied Publishers.

Valli, E. (1998). "Golden Harvest of the Raj." National Geographic 193: 86-105.

van Huis, A. (1991). "Biological methods of Bruchid control in the Tropics: A review." Insect Science and its Application 12: 87-102.

van Huis, A. (1996). "The traditional use of Arthropods in Sub Saharan Africa." In Proceedings of the Section Experimental and Applied Entomology of the Netherlands Entomological Society 7: 3-18.

van Huis, A., R. S. Nauta, and M. E. Vulto (1982). "Traditional Pest Management in Maize in Nicaragua." Mededelingen Landbouwhogeschool Wageningen 82: 1-43.

Warren, D. M. (1989). "Linking scientific and indigenous agricultural systems." In J. L. Compton (ed.), The Transformation of International Agricultural Research \& Development (pp. 153-170). London: Lynne Rienner.

Warren, D. M. (1991). Using Indigenous Knowledge in Agricultural Development. Washington, DC: The International Bank for Reconstruction and Development, Report No. 127.

Warren, D. M. and G. McKiernan (1995). "CIKARD: A global approach to documenting indigenous knowledge for development." In D. M. Warren, L. J. Slikkerveer, and D. Brokensha (eds.), The Cultural Dimension of Development - Indigenous Knowledge Systems (pp. 426-434). London: Intermediate Technology.

Weller, S. (1987). "Shared knowledge, intracultural variation, and knowledge aggregation." American Behavioral Scientist 31: 178-193.

Weller, S. C. and A. K. Romney (1988). Systematic Data Collection (Qualitative Research Methods; Vol. 10). London: Sage Publications.

Werner, O. and J. Fenton (1970). "Method and theory in ethnoscience or ethnoepistemology." In R. Naroll and R. Cohen (eds.), A Handbook of Method in Cultural Anthropology (pp. 537-578). New York: The Natural History Press.

Wierzbicka, A. (1996). Semantics: Primes and Universals. Oxford: Oxford University Press.

Wyman, L. C. and F. Bailey (1964). "Navaho Indian ethnoentomology." University of New Mexico Publications in Anthropology 12.

Address for correspondence: Astrid Björnsen Gurung, The Mountain Research Initiative, Bärenplatz 2, 3011 Berne, Switzerland

Phone: + 41-31-3282330; Fax: +41-31-3282320;

E-mail: bjoernsen@sanw.unibe.ch 